\title{
Review Article \\ Recent Advances in the Synthesis, Properties, and Biological Applications of Platinum Nanoclusters
}

\author{
Xin Huang $\mathbb{D}^{1},{ }^{1}$ Zengbei Li, ${ }^{1}$ Zhengguo Yu, ${ }^{1}$ Xinjie Deng, ${ }^{1}$ and Yi Xin ${ }^{2}$ \\ ${ }^{1}$ School of Textiles, Zhongyuan University of Technology, Zhengzhou 450007, China \\ ${ }^{2}$ Department of Respiratory and Critical Care Medicine, The Fifth Affiliated Hospital of Zhengzhou University, \\ Zhengzhou 450052, China
}

Correspondence should be addressed to Xin Huang; xinhuang@zut.edu.cn

Received 3 April 2019; Accepted 12 July 2019; Published 8 September 2019

Guest Editor: Teofil Jesionowski

Copyright @ 2019 Xin Huang et al. This is an open access article distributed under the Creative Commons Attribution License, which permits unrestricted use, distribution, and reproduction in any medium, provided the original work is properly cited.

\begin{abstract}
Noble metal nanoclusters (M NCs), defined as an aggregation of a few to tens of atoms, are considered a borderline between atoms and metal nanoparticles (M NPs), which tends to exhibit molecule-like behaviours such as discrete electronic state and sizedependent fluorescence. In the past decades, gold and silver nanoclusters (Au NCs and Ag NCs) have been massively explored and utilized in the field of industrial catalysis, optoelectronic devices, biological imaging, environmental detection, clinical diagnoses, and treatment. The analogue of $\mathrm{Au}$ and $\mathrm{Ag} \mathrm{NCs}$ and platinum nanoclusters (Pt NCs), especially their biological applications, is relatively and rarely discussed. This review firstly investigates the synthetic methodology of Pt NCs including template-assisted and template-free approaches and then introduces their unique optical, catalytic, and thermal properties. Particular importance here is the biological applications of Pt NCs such as the bioimaging of various cells as a preferred fluorophore in contrast to traditional fluorescent markers (e.g., organic dye, semiconductor quantum dots, and fluorescent proteins), the usage of Pt NCs-based antitumour drugs as a new class chemotherapeutics for malignant tumour therapy, and the utilization of antibacteria as an alternative of Ag-based antibacterial agent. On the whole, the development of Pt NCs has already gained delectable progress; however, the study of ultrafine Pt NCs is at the beginning stage and there are still plenty of challenges like synthesis of near-infrared (NIR) fluorescent Pt NCs, the explicit signal pathway of cell apoptosis, and attempt in diverse biological applications that need to be urgently tackled in future.
\end{abstract}

\section{Introduction}

Noble metal like rhodium $(\mathrm{Rh})$, palladium $(\mathrm{Pd})$, silver $(\mathrm{Ag})$, platinum $(\mathrm{Pt})$, and gold $(\mathrm{Au})$ is one kind of modish and desired material, according to their inherent resistance to oxidation and corrosion even in the moist environment [1-3]. Its physical and chemical properties appear to be entirely change as the size of metal continuously decreases into nanoscale because of the quantum size effect, surface effect, small size effect, and macroquantum tunnel effect [4]. For example, noble metal nanoparticles (M NPs) which are defined as the particle size ranged from 1 to $100 \mathrm{~nm}$ have the high surface-to-volume ratio and electrodynamic interaction, leading to emerge distinct electronic, magnetic, and optical properties in contrast to bulk counterparts or individual atoms $[5,6]$. In view of freely moving deloca- lized electrons in the conduction band, metals in a bulk state are good optical reflectors and electrically conducting (Figure 1). As for M NPs, a specific size-dependent plasma absorption will be presented when the size is smaller than the average free path length of conduction electrons (i.e., $<20 \mathrm{~nm}$ ) based on Mie's theory [7, 8]. If the M NPs are irradiated by light, strong optical absorption and/or scattering phenomenon will happen forcefully relied on their size, morphology, and dielectric environment, which is recognized as localized surface plasmon resonance (LSPR) [9-11]. Consequently, M NPs show the intense colours owing to the collective oscillation of conduction electrons upon interaction with light and this particular property has been widely developed in catalysis, optoelectronics, sensing, and surface-enhanced Raman scattering (SERS) [12-16]. Further declining the size of metal nanomaterials 


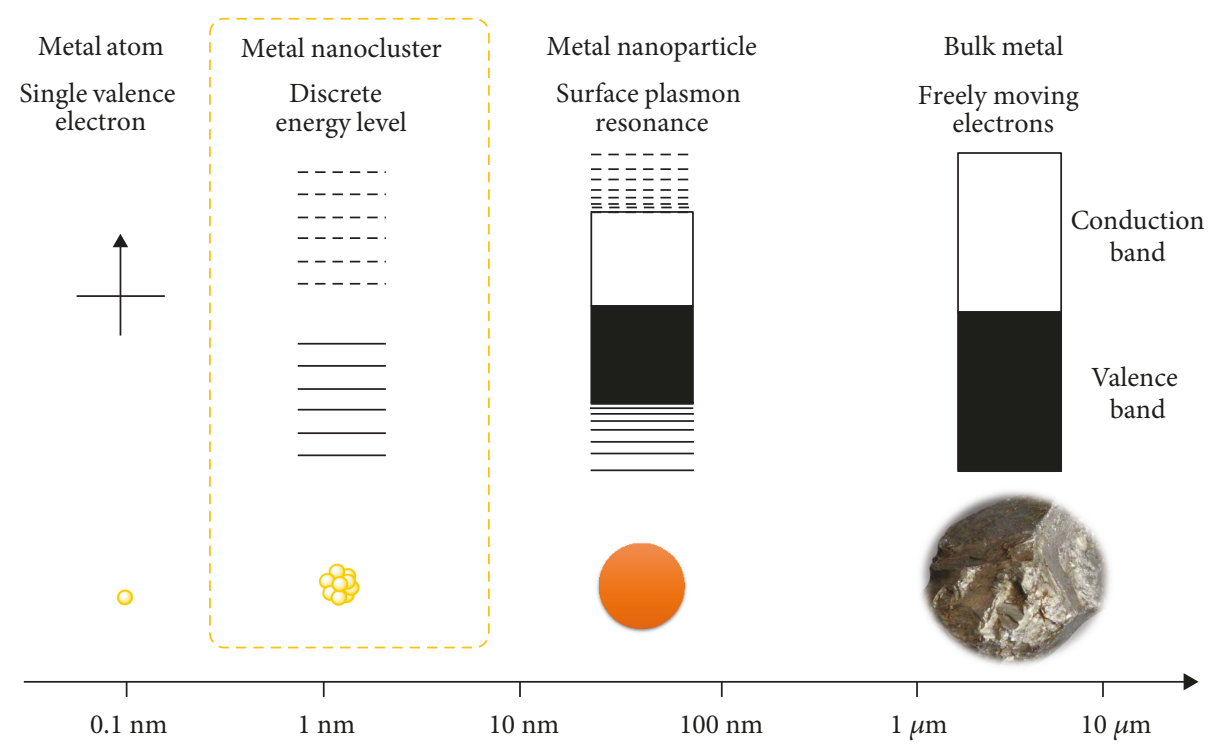

Figure 1: Schematic representation for size effect of metals. M NCs are a borderline between M NPs and atoms.

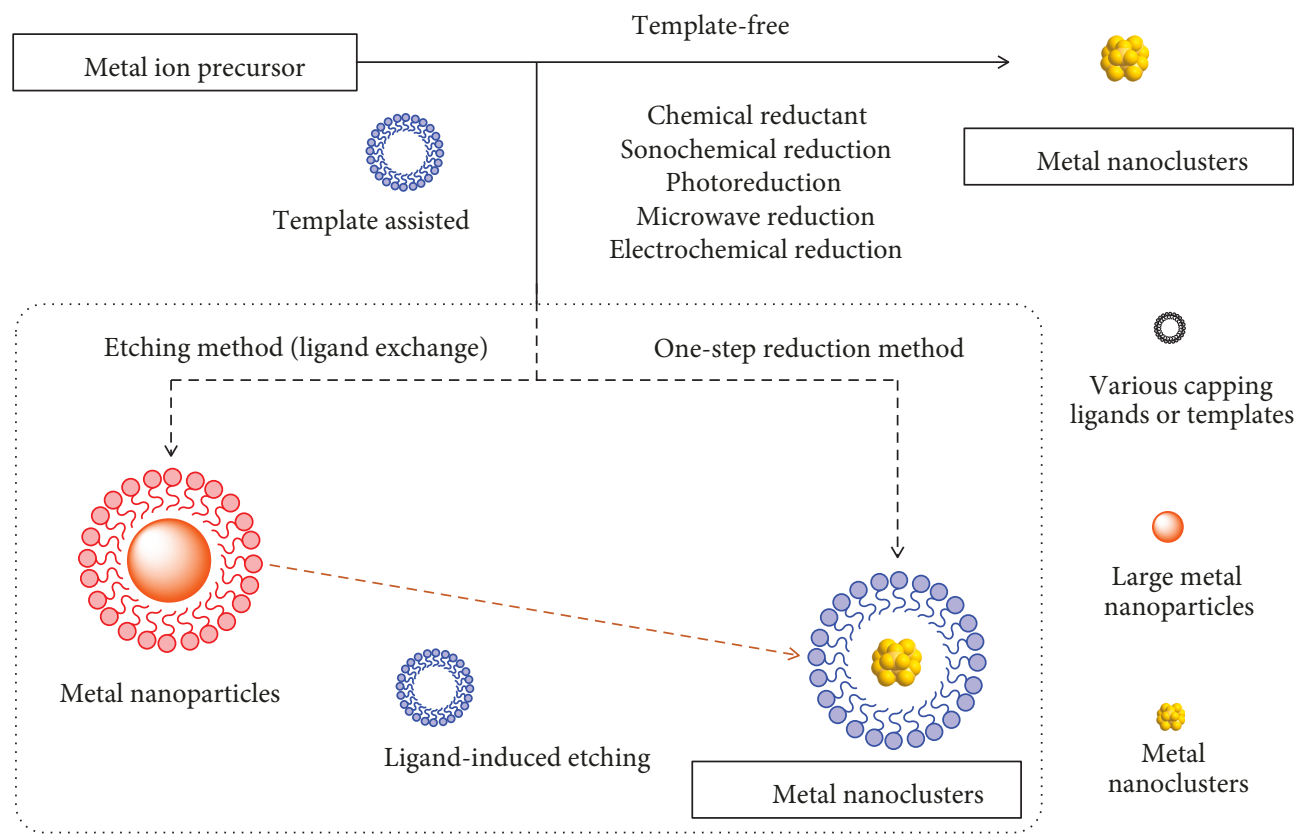

FIGURE 2: Schematic route for common synthesis of Pt NCs.

into around $0.1-2 \mathrm{~nm}, \mathrm{M}$ NPs turn into metal nanocluster (M NC) region [17]. M NCs as a borderline between M NP and atoms were firstly discovered by Cotton and Haas in 1964 [18]. On this length scale, the electronic band structure of M NCs is broken down into discrete energy levels under the condition of free electrons' size near Fermi wavelength (i.e., $<2 \mathrm{~nm}$ ), resulting in the acquisition of molecule-like behaviours like the discrete electronic state [19-21]. Moreover, M NCs exhibit the intense light absorption and emission by the interaction between NCs and light via electronic transitions between energy levels. This unique electronic properties of M NCs are potently depended on their size, morphology, metal oxidation state, and surrounding ligands [22, 23]. Thus, a plenty of efforts focused on the preparation of desired and versatile M NCs by precise control of their sizes or shapes through meticulously choosing stabilized ligands or templates and the usage of NCs in an optical device [24, 25], chemical detection [26-29], catalytic conversion [30], and especially in biological applications [31].

Platinum $(\mathrm{Pt})$, as one of the representative noble metal, has the physicochemical stability and remarkable resistance to corrosion even at high temperature based on its steady electrical structure [2]. Its physical and chemical inertness makes Pt widely employ in the fundamental industrial fields such as electrodes, dentistry equipment, $\mathrm{Pt}$ resistance 


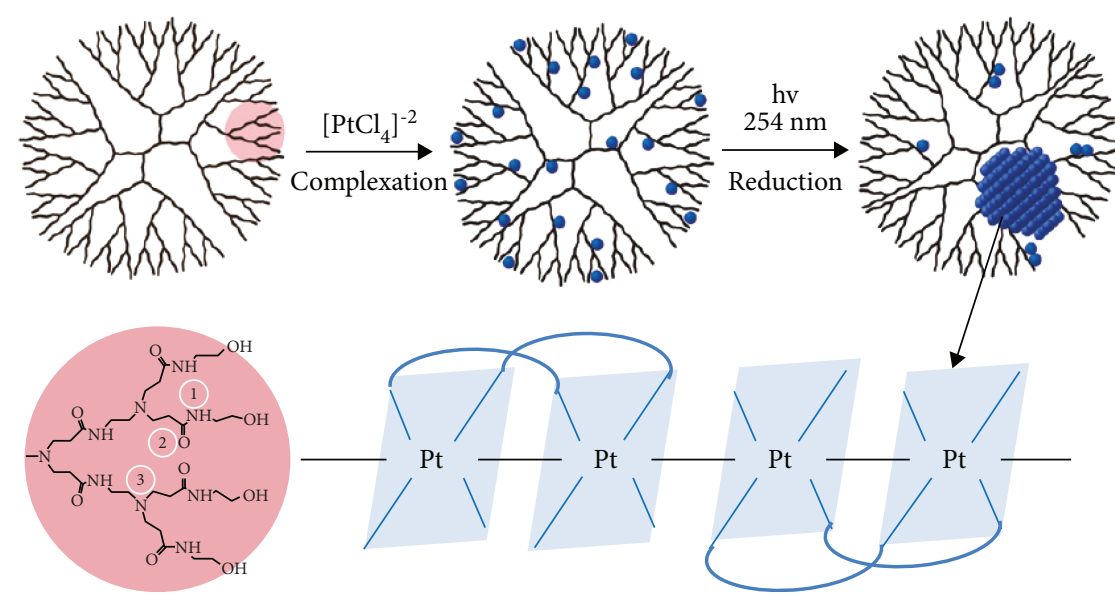

(a)
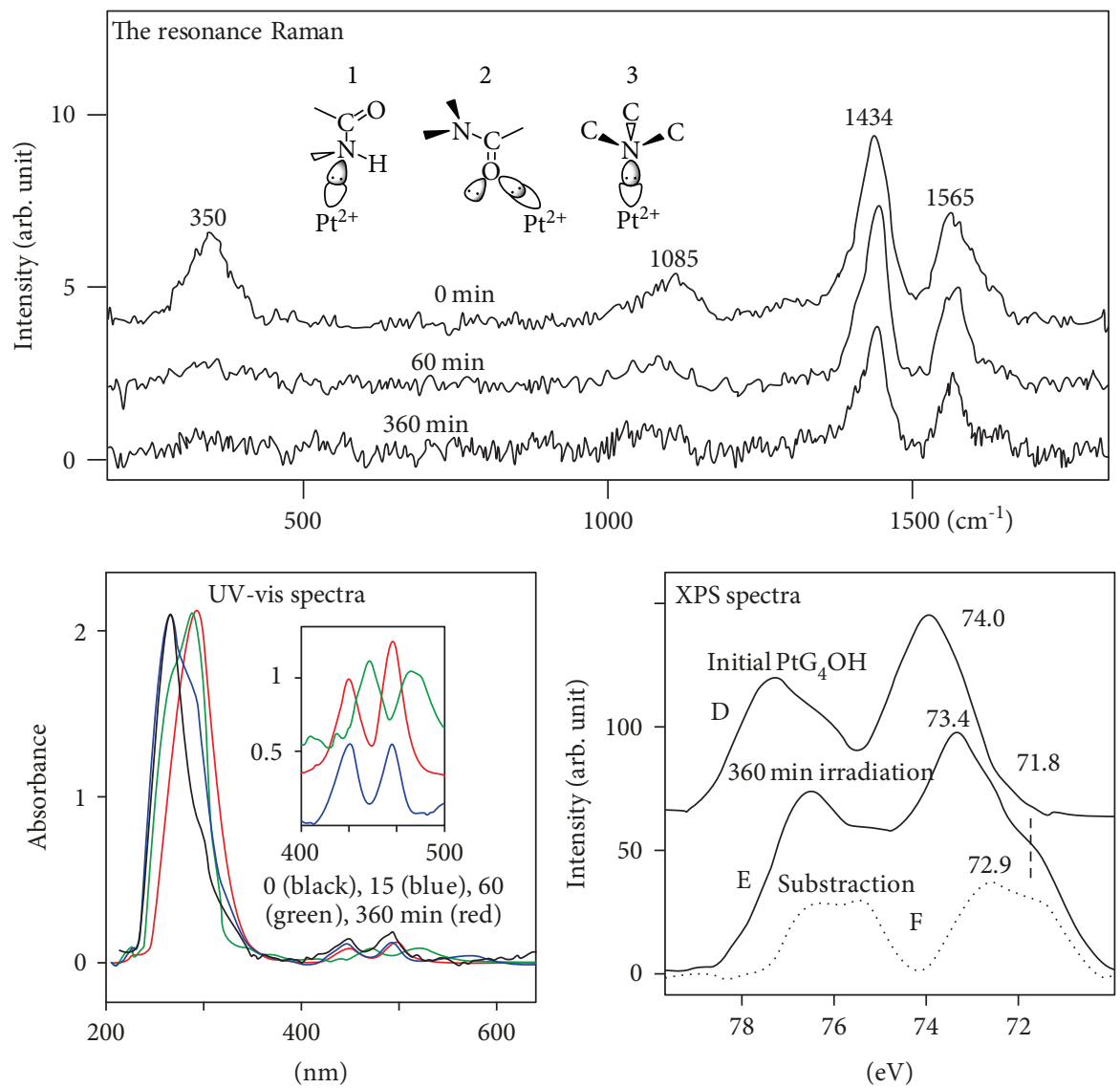

(b)

Figure 3: Continued. 


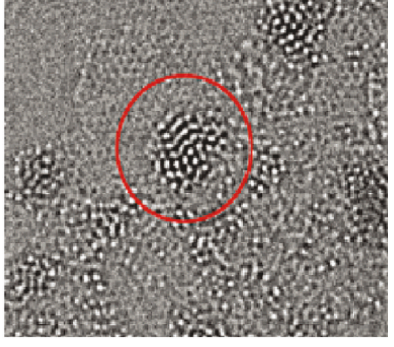

$0 \mathrm{~s}$

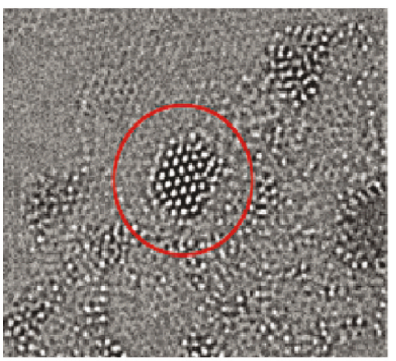

$12 \mathrm{~s}$

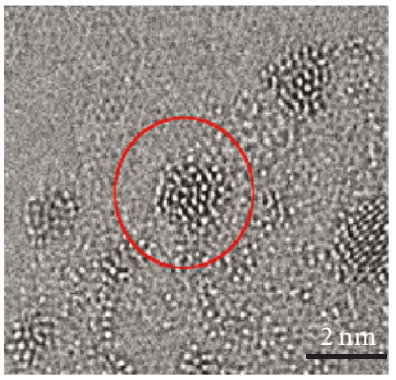

$15 \mathrm{~s}$

(c)

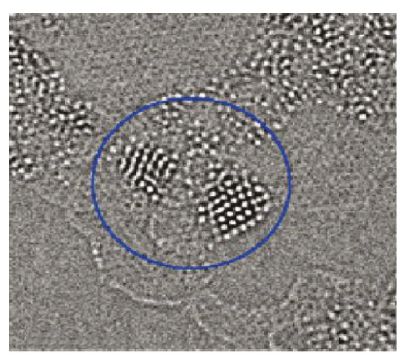

$0 \mathrm{~s}$

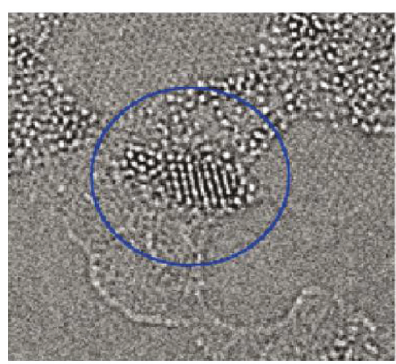

$15 \mathrm{~s}$

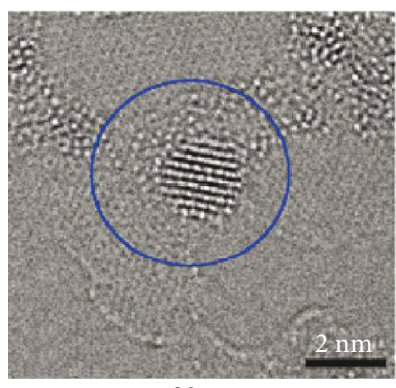

$30 \mathrm{~s}$

(d)

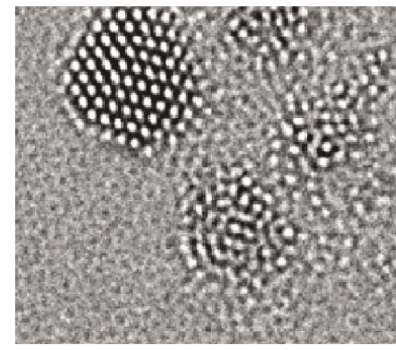

$0 \mathrm{~s}$

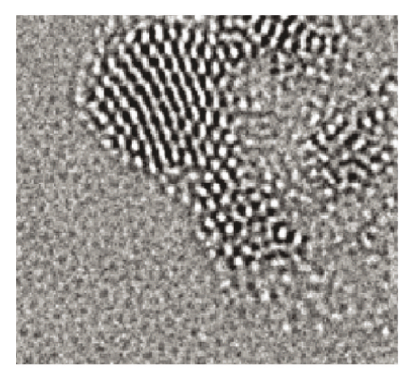

$15 \mathrm{~s}$

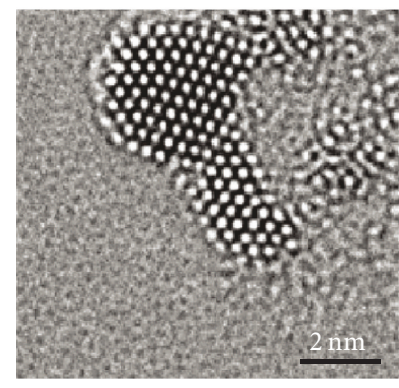

$19.5 \mathrm{~s}$

(e)

FIgure 3: (a) Schematic process of the formation of Pt NCs using a dendrimer as a template under the UV light irradiation. (b) The resonance Raman, UV-vis, and XPS spectra of synthesized Pt NCs. The HR-TEM of dynamic transformation of Pt NCs at (c) metastable mesocrystal, (d) mesocrystal combination, and (e) oriented crystal, as the irradiation time increased (reprinted major modification with permission from [72], Copyright 2012, American Chemical Society).

thermometers, and catalytic converters [2, 32]. The fabrication and application of Pt materials on the subnanoscale became a research hotspot in the past few decades, especially in the catalysis and medicine. The most common utilizations of Pt nanomaterials are the catalysis of chemical reaction according to their high surface activity [33]. Based on their scarcity and preciousness, the research priorities of Pt materials are aimed at developing high-performance Pt-based materials through enhancing the catalytic efficiency as well as decreasing the usage amount. Undoubtedly, Pt's size and morphology play a critical and indispensable role [34]. On the other hand, Pt-based antineoplastic agents (like cisplatin, oxaliplatin, and carboplatin) have been universally used in the clinical chemotherapy against multiple cancers [35]. For example, $\mathrm{Pt}(\mathrm{II})$ anticancer drugs could induce the crosslinking of DNA, leading to the inhabitation of DNA synthesis or repair in tumour cells [36].

Up to now, typical Pt NPs demonstrated their applicable and prospective capacities in enormous areas such as gas detection, fuel cells, biosensors, and chemotherapeutics
[37]. Besides, the analogues of Pt NCs, namely, Au NCs [38, 39], Ag NCs [40], Pd NCs [41] and Cu NCs [42], have been intensively investigated for their catalytic abilities, biological behaviours, and electrical and optical properties. By comparison of well-studied Pt NPs or congeneric NCs, the investigation of Pt NCs is just at an early stage in the last few decades; herein, this review summarizes the recent advance in the synthetic method of Pt NCs and special physicochemical properties, especially their fascinated biological applications.

\section{Synthetic Method of Platinum Nanoclusters}

In comparison to metal bulk or M NPs, the preparation of Pt $\mathrm{NCs}$ refers to the precise control and rigorous synthetic conditions due to their extreme small size [43]. There are many classification standards of the preparation method (Figure 2) [44-47], like physical and chemical method and one-pot and etching method. We generally divided the 

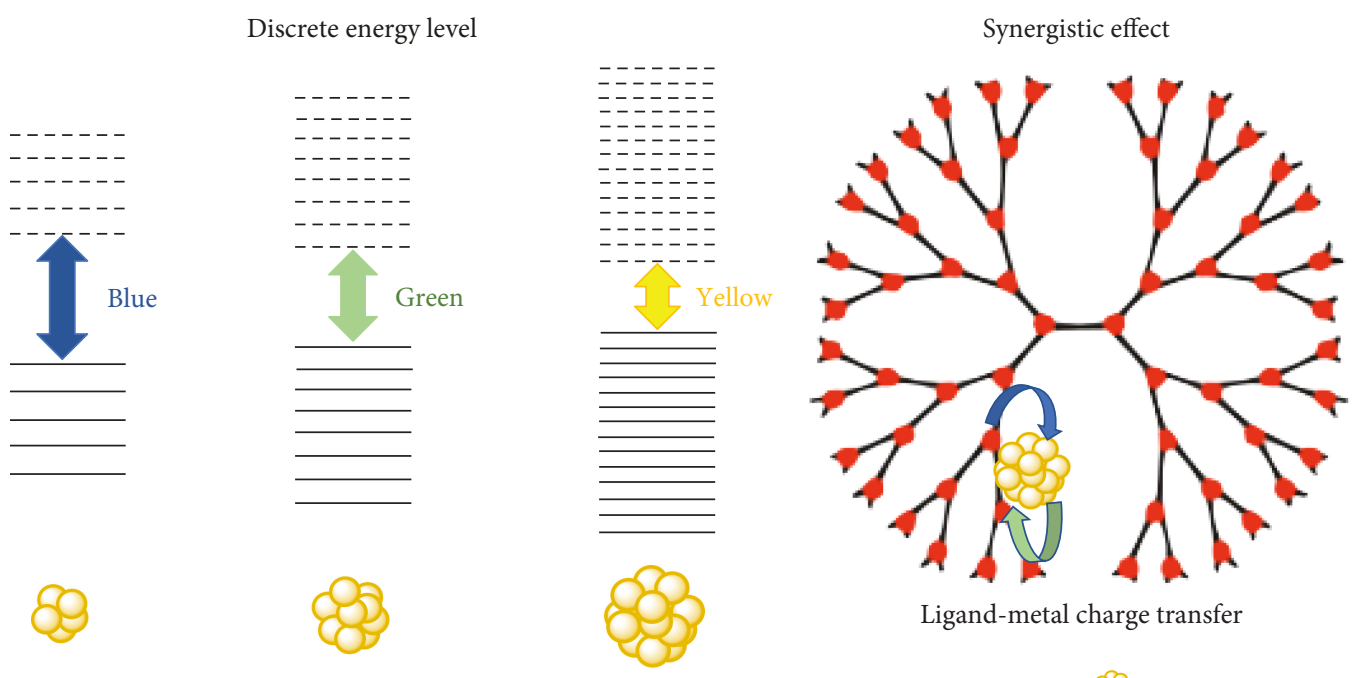

Ligand-metal charge transfer

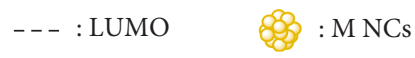

Size-dependent fluorescence

: M NCs

--- : LUMO

: template ligand

(a) (b)

FIGURE 4: Schematic mechanism for (a) size-dependent fluorescence of Pt NCs and (b) the synergistic effect between metal and surrounding ligands.

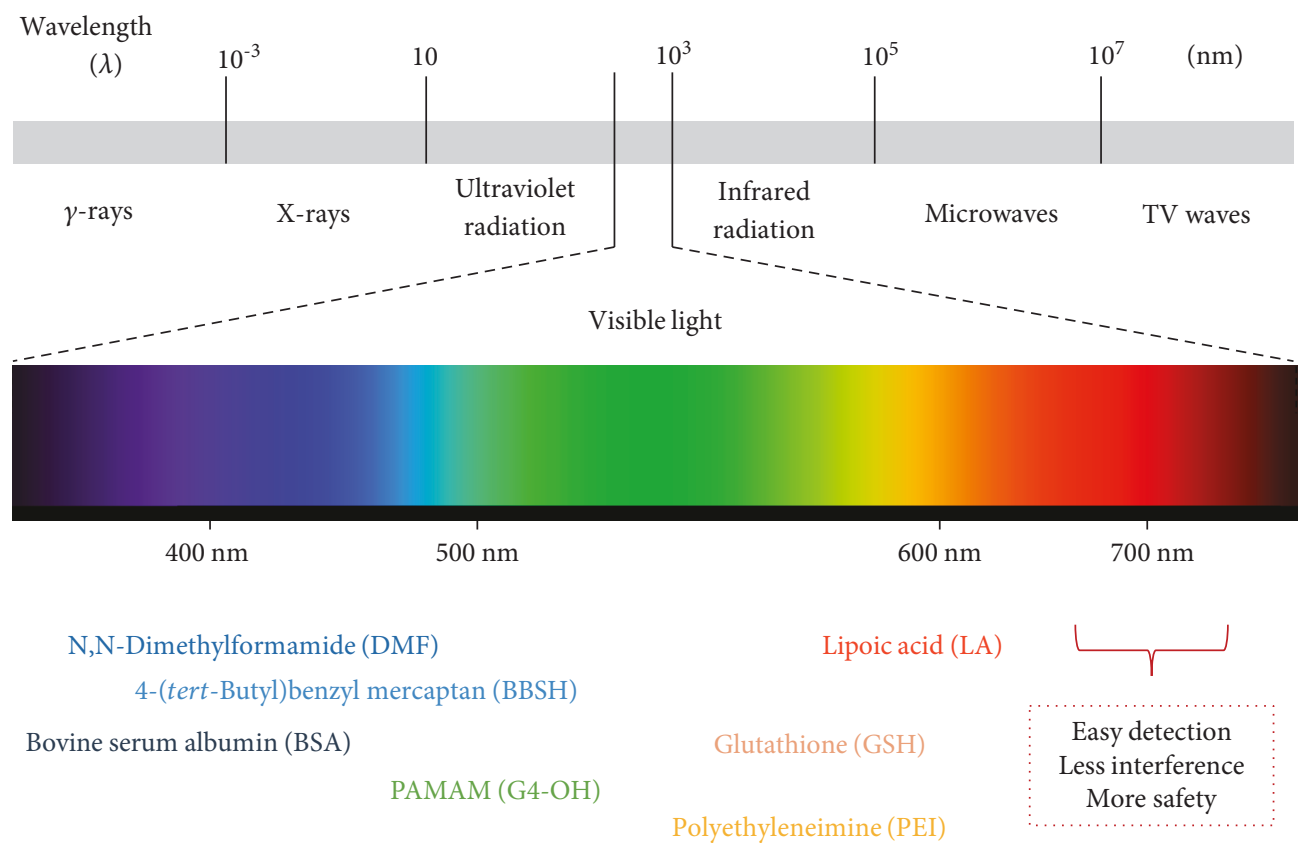

FIGURE 5: Schematic diagram of the used template for synthesizing fluorescent Pt NCs and the corresponding visible fluorescent emission region.

synthetic protocols of Pt NCs into two aspects: templateassisted method and template-free method.

2.1. Template-Assisted Method. Template-assisted method is based on the presence of various templates during the synthetic process, which plays a role as a protecting agent, a stabilizer, a capping agent, and even as the restrict space provider. The usual templates impart the M NCs' new unique features or specific structure by means of three main ways [3]: (1) decline of the surface energy to prevent the NCs' aggregation via electrostatic interaction, chemical bonding, and space steric effect; (2) accurate control and tailor of $\mathrm{M}$ NCs' size, dispersity, and morphology, which will profoundly influence, determine, and enhance their inherent functions; 


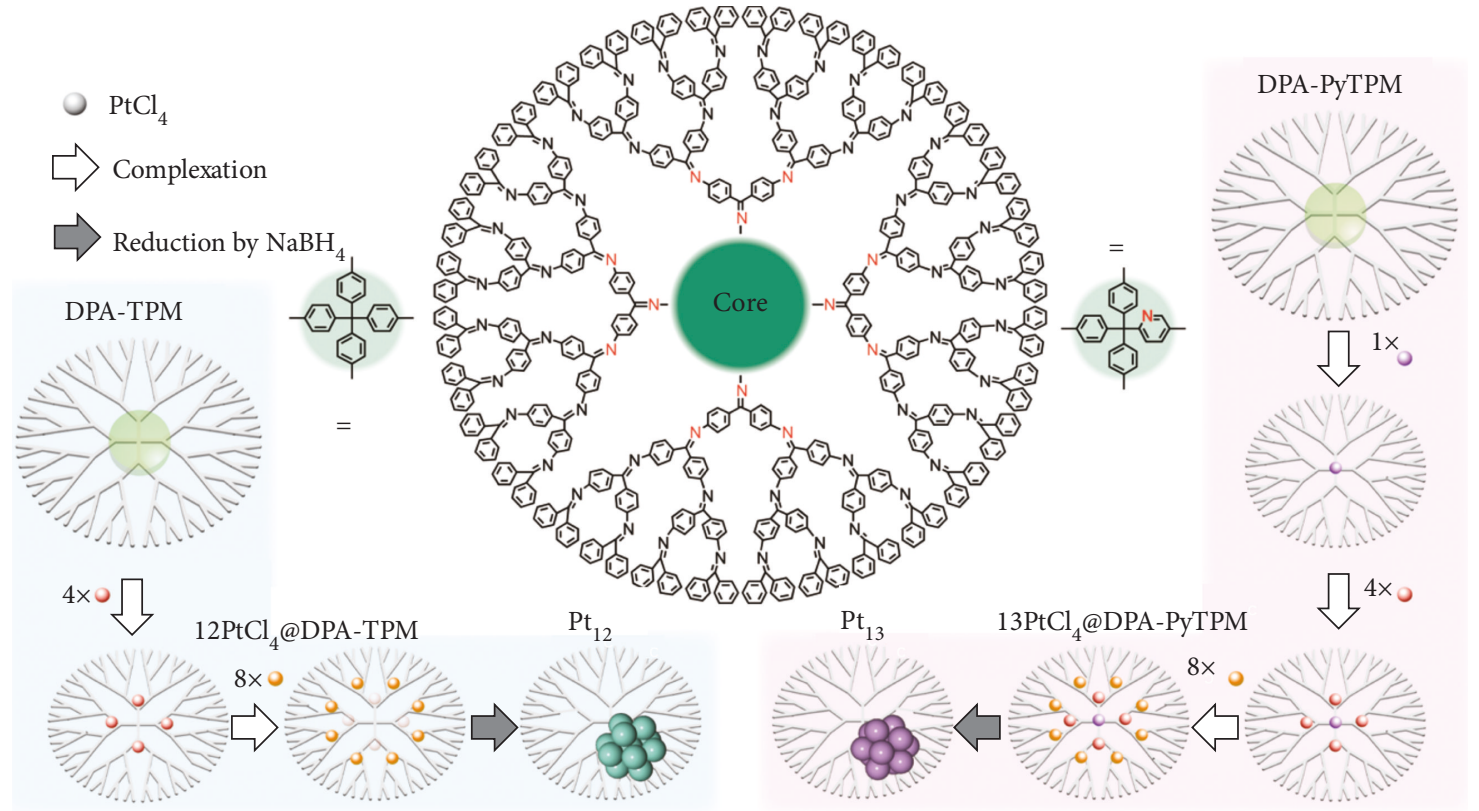

(a)

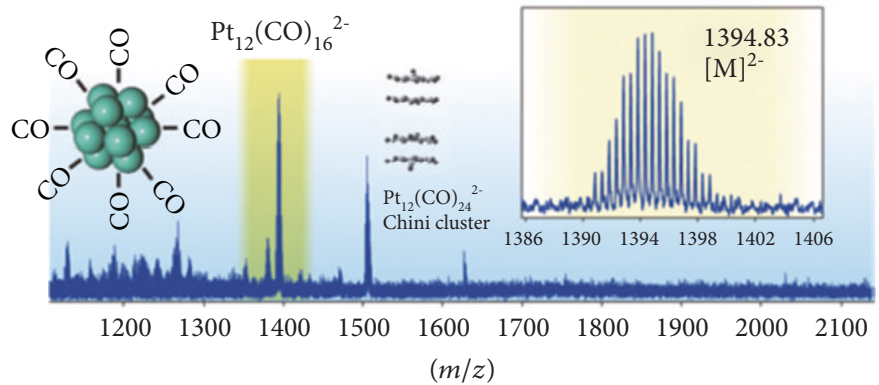

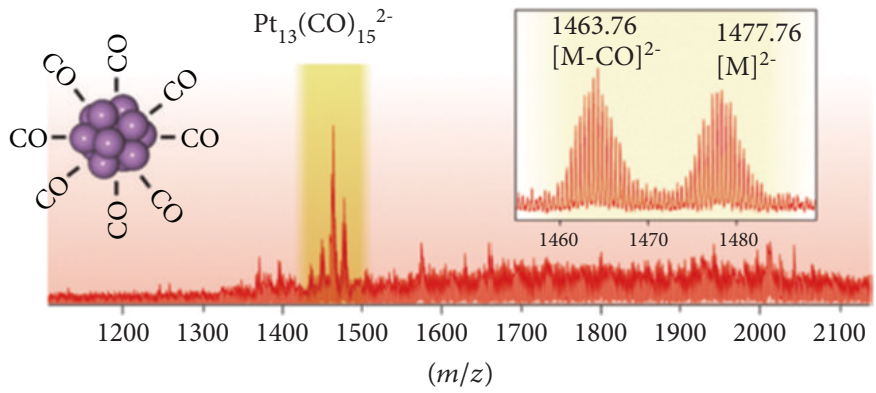

(b)

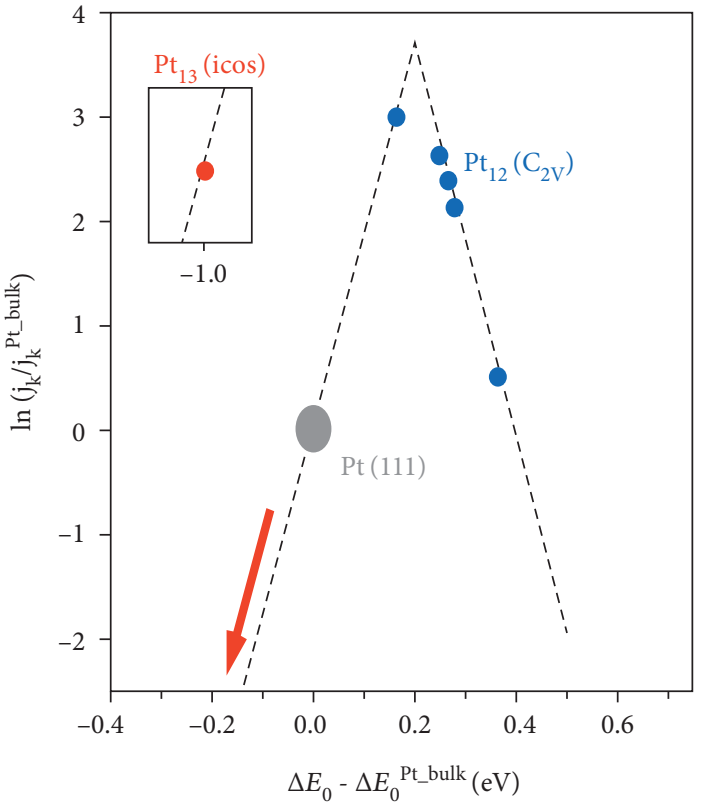

(c)

Figure 6: Continued. 

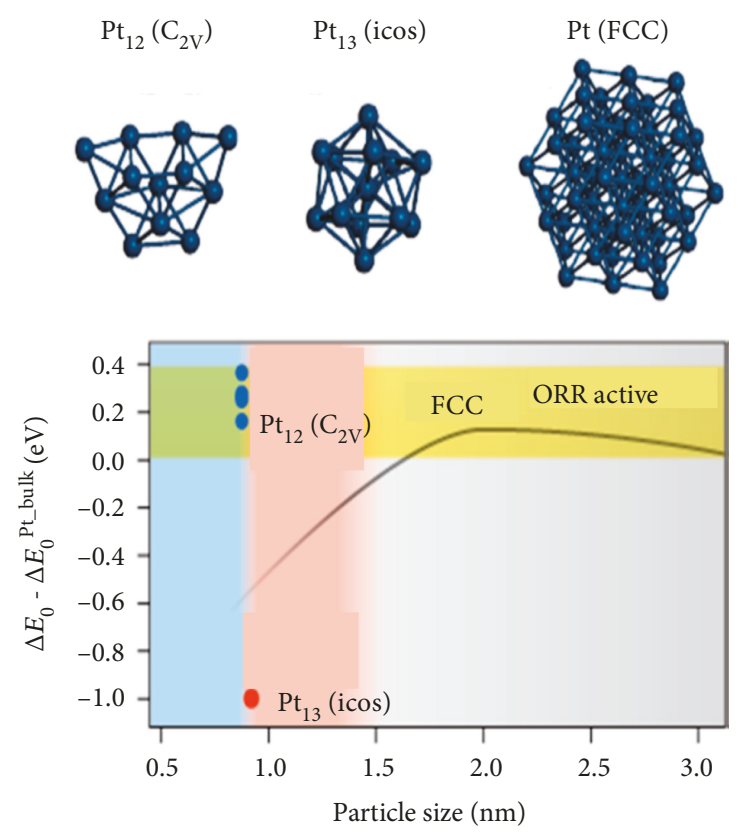

(d)

FIgURE 6: (a) Schematic process of preparing $\mathrm{Pt}_{12}$ and $\mathrm{Pt}_{13}$ NCs employed DPA-TPM and DPA-PyTPM as the template, respectively. (b) The electrospray ionization time of flight mass spectrometry (ESI-TOF-MS) of Pt NCs after ligand exchange by CO gas. (c) The diagrams of relationship between kinetic current density $\left(j_{\mathrm{K}}\right)$ and calculated oxygen adsorption energy $\left(\Delta E_{0}\right)$ for ORR using Pt-based catalyst, e.g., $\mathrm{Pt}_{12}, \mathrm{Pt}_{13}$, and $\mathrm{Pt}_{(11)}$. (d) Simulated structures for optimized geometry of $\mathrm{Pt}_{12} \mathrm{NCs} \mathrm{Pt}_{13} \mathrm{NCs}$, and FCC-structured Pt NPs and the relationship diagram of relative $\Delta E_{0}$ and particle size (reprinted major modification with permission from [155], Copyright 2013, American Chemical Society).

and (3) decoration and modification of the M NCs' surface to endow some reactive functional groups in order to achieve the further applications. The ideal templates always include electron-rich atoms (e.g., N, P, S, and O) or certain functional groups (e.g., - $\mathrm{COOH},-\mathrm{NH}_{2},-\mathrm{OH}$, and $-\mathrm{SH}$ ).

Common templates utilized during the synthesis of $\mathrm{M}$ NCs are small organic molecules like representative surfactant, thiol compounds, organophosphorus compounds, and amino compounds [48-51]. Polymer ligand including nonionic and ionic polymers (such as acrylic polymer, amine polymer, polyethylene glycol, poly(N-vinyl-2-pyrrolidone), polypyrrole, and dendrimer) is another widely used template materials [52-54]. A polymer template stabilizes the NCs by chemical bonding and electrostatic effect, as well as steric effect due to large spatial configuration. Compared to small organic molecules, polymer has the easier modification, better controlling ability, and lower toxicity $[55,56]$, making them a preferred option for synthesis of M NCs. Furthermore, a biomacromolecule template, such as DNA, protein, oligonucleotides, and enzymes, is a kind of prevalent materials used to manufacture the medical and biological metal nanomaterials $[57,58]$. Biomacromolecule is always relative to a specific biomolecular recognition function, multifunctional group (-SH, $-\mathrm{COOH},-\mathrm{OH}$, and $-\mathrm{NH}_{2}$ ), and excellent biocompatibility [59], showing a promising potential in the development of various biofunctional M NCs. In general, a template cannot reduce the metal precursor to form the $\mathrm{M}$ NCs without adding any other chemical redundant or with the help of physicochemical means such as the $\gamma$-radiolysis method [60], microwave-ultrasonic method [61], sonochem- ical method [62], photoreduction method [63], and electrochemical method [64].

Chemical etching method also called ligand-induced exchange etching involves two processes: the larger-sized $M$ NPs are formed firstly under the stabilized template with a weak interaction and secondly, ligand-induced etching of larger-sized NPs occurs under the existing excess ligands by a strong interaction between ligands and metal atoms to produce smaller size NCs. Highly blue fluorescent Pt NCs with two peaks at $410 / 436 \mathrm{~nm}$ were synthesized by phase transfer through electrostatic interactions under an etching environment [65]. The presynthesized glutathione- (GSH-) protected Pt NPs were transferred into organic solvent with the support of cetyl trimethyl ammonium bromide (CTAB) to secondly form the fluorescent small Pt NCs. However, this method is always related to a time-consuming and complicated process, which is not suitable for the production of $\mathrm{M}$ NCs at a large scale.

Direct reduction in the present of templates and extra chemical reductant is a classical and extensive way to acquire the small size NCs. Atomically precise Pt NCs which consist of 11 atoms ( $\left.\mathrm{Pt}_{11} \mathrm{NCs}\right)$ were obtained by a direct chemical reduction using small molecule 4-(tert-butyl)benzyl mercap$\tan (\mathrm{BBS})$ as the template and sodium borohydride $\left(\mathrm{NaBH}_{4}\right)$ as the reducing agent [66]. The structure of NCs was defined as $\mathrm{Pt}_{11}(\mathrm{BBS})_{8}$ by matrix-assisted laser desorption-ionization mass spectrometry (MALDI-MS) and electrospray ionization (ESI) technology. Moreover, special octahedral Pt NCs were successfully synthesized employing glucose as the reducing agent and $\mathrm{CTAB}$ as the shape-control templates via one-pot 


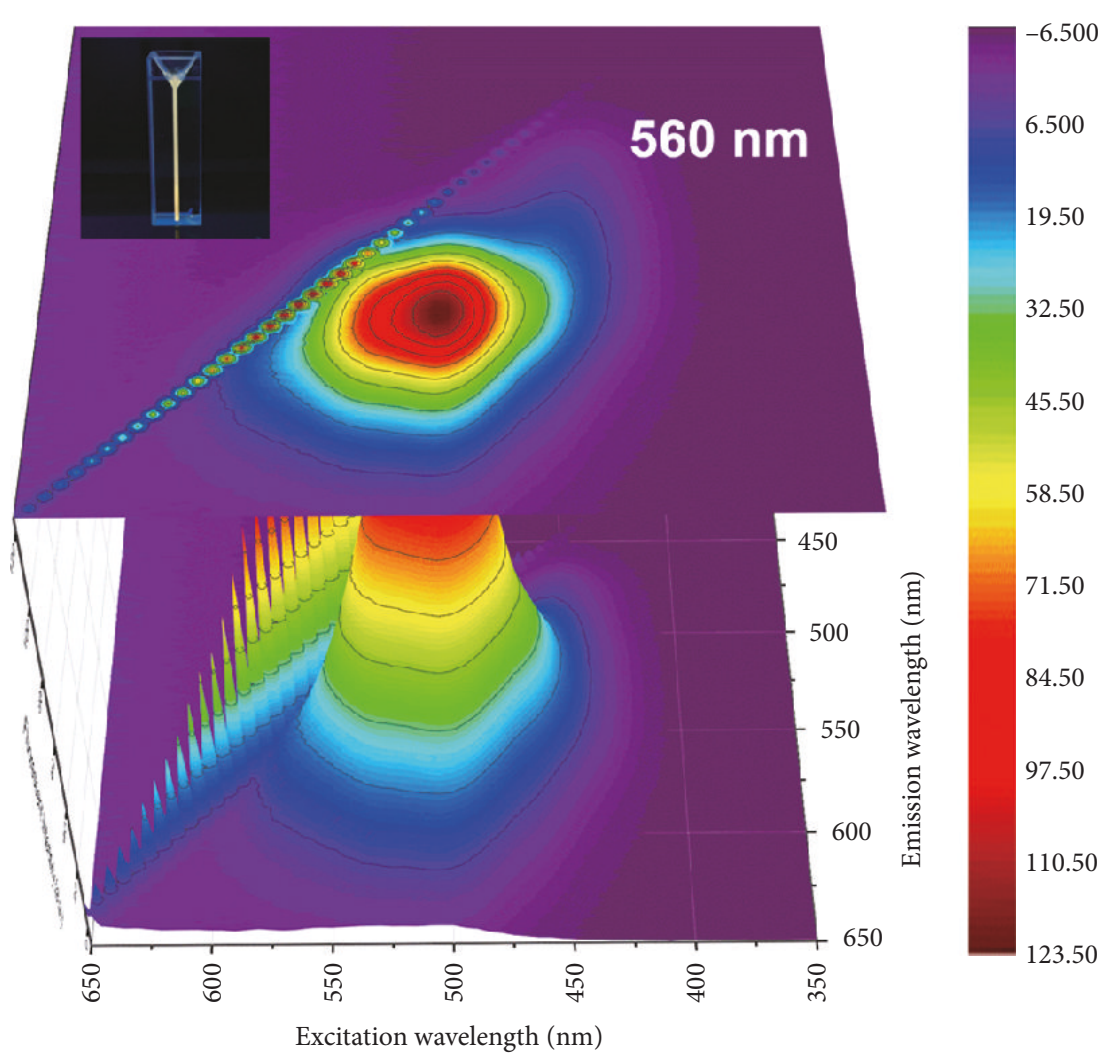

(a)

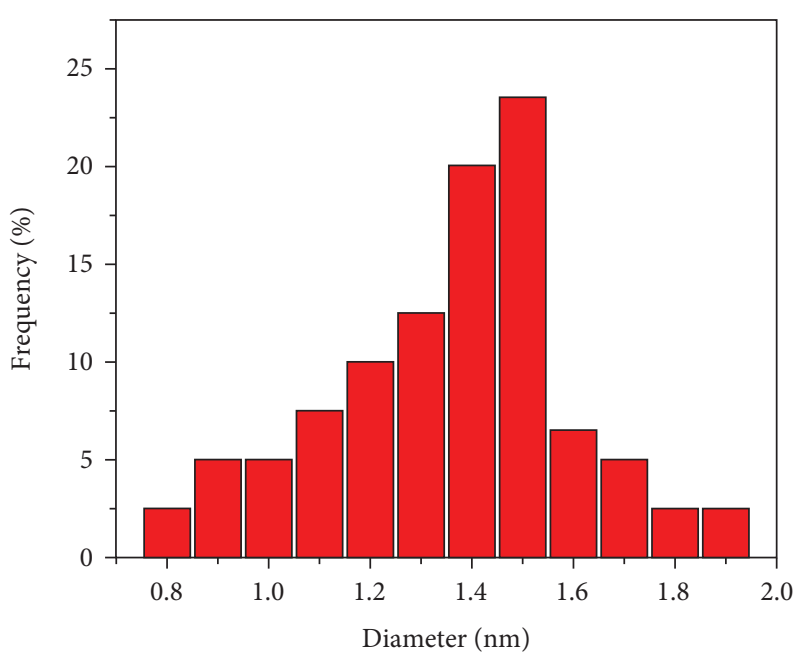

(c)

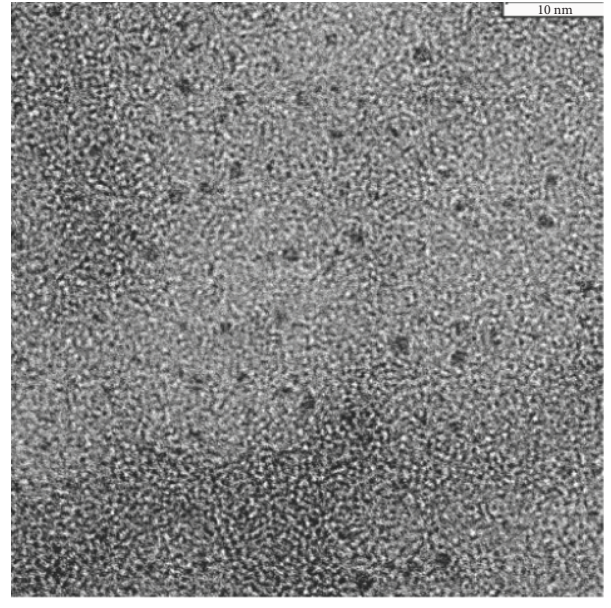

(b)

Figure 7: Continued. 

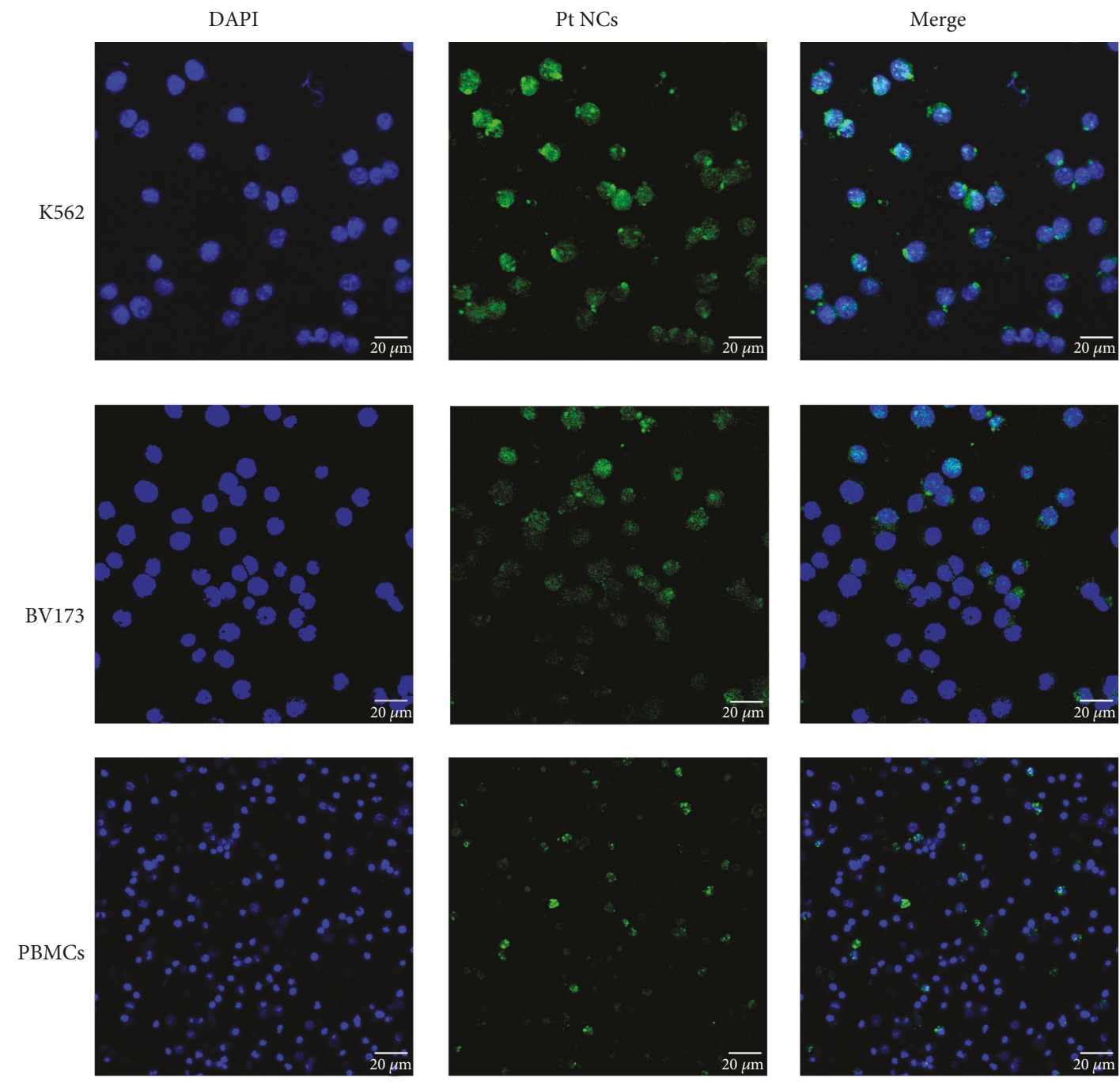

(d)

FIgURE 7: (a) 3D fluorescence spectra of Pt NCs. Insert is the photograph of Pt NCs under $365 \mathrm{~nm}$ UV irradiation. (b) TEM pictures of Pt NCs and (c) corresponding size distribution histogram. (d) Confocal microscopic photographs of K562, BV173 cancer cells, and normal PBMC cells after cultured with Pt NCs for $4 \mathrm{~h}$. DAPI is employed to stain the cell nuclei emitting blue fluorescence, and Pt NCs show the green fluorescence (the scale bar is $20 \mu \mathrm{m}$ ) (reprinted major modification with permission from [186], Copyright 2018, Elsevier).

hydrothermal process [67]. The formation mechanism of octahedral NCs is that glucose reduces Pt ions into atoms and then atoms grow to octahedron by the precise control of CTAB, namely, the synergetic effect both of CTAB and glucose. Cho et al. put forward the sol-gel polymerization protocol of poly(2-hydroxyethyl-2-mercaptoethyl aspartamide) (PHMA) capped Pt NCs [47]. PHMA as a polymer template could control the morphology of NCs and organize their structure association, based on binding Pt procurers via amine functional groups and particles via thiol functional groups. For another instance, dendrimer, as a favourable template, has a uniform structure which can supply a predetermined formation environment to accurately control the NCs' size and morphology [68-71]. A linear structural Pt NCs with 4-8 atoms were fabricated inside of polyamidoamine dendrimer by UV irradiation at $254 \mathrm{~nm}$ (Figure 3) [72]. The tools of resonance Raman spectra, ultravioletvisible (UV-Vis) spectroscopy, X-ray photoelectron spectros- copy (XPS), and high-resolution transmission electron microscopy (HR-TEM) were employed to clarify that the assemble of Pt nanocrystals is owing to an oriented attachment mechanism.

Physicochemical technique can assist the preparation of ultrafine Pt NCs, instead of using chemical reductants. Microwaves, as the electromagnetic waves, could obtain monodispersed M NCs by the fast and homogeneous heating [61]. Microwaves heat polar molecules rapidly at the high temperature without heating the glass container, leading to the formation of colloidal metal nanomaterials. The synthesized M NCs are always related to the high quality and narrow size distribution. Tu and Liu employed microwave irradiation to prepare the poly( $\mathrm{N}$-vinyl-2-pyrrolidone)-supported Pt NCs with an average size at $1.52 \pm 0.26 \mathrm{~nm}$ [73] This method could continuously produce the uniform $\mathrm{Pt}$ NCs even at a large scale, satisfying industrial applications. Photoreduction is a simple, feasible, and nontoxic approach 


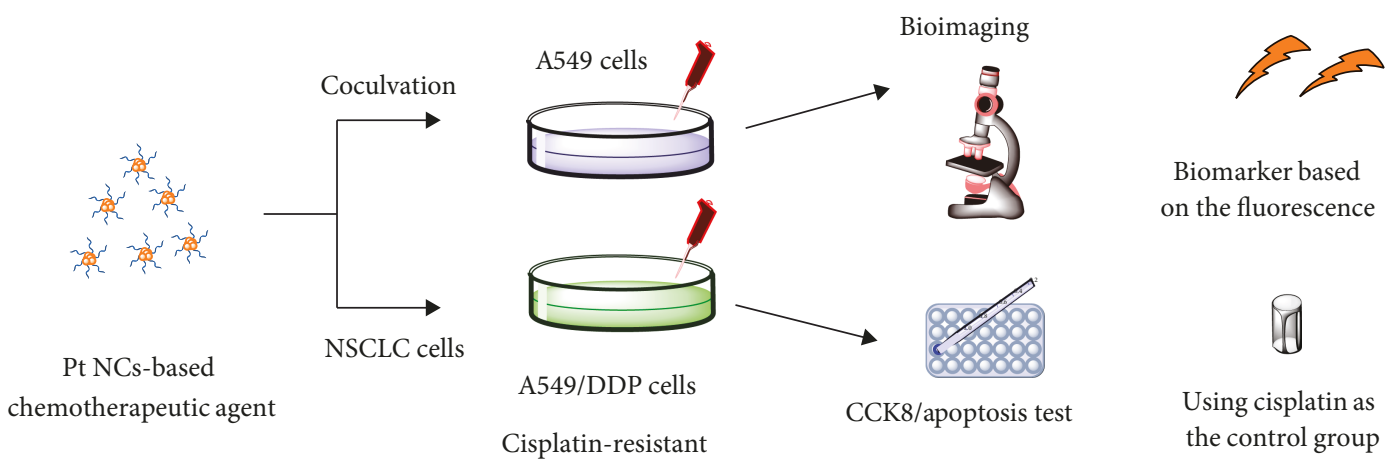

(a)

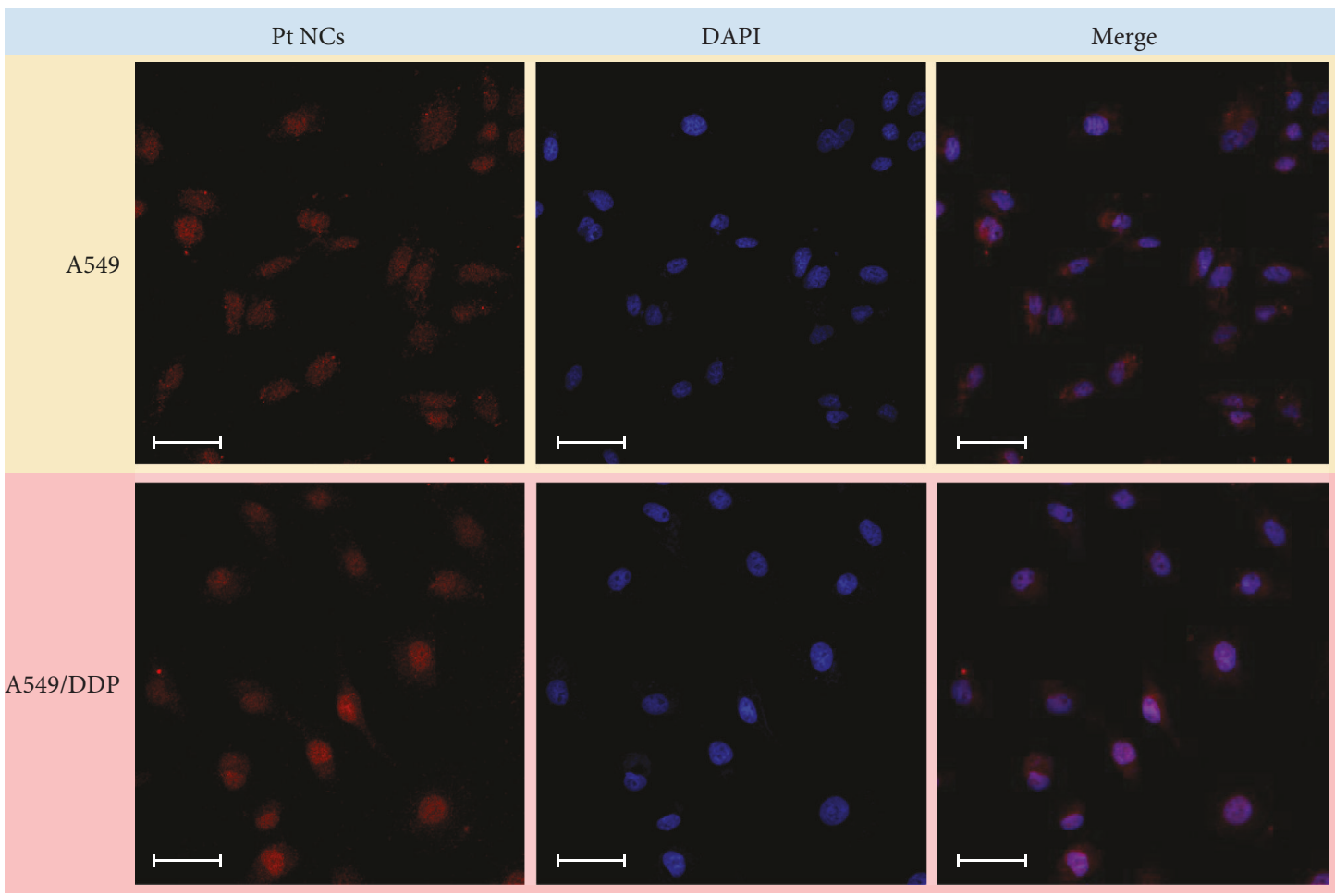

(b)

FIGURE 8: (a) The schematic process of bioimaging of human lung adenocarcinoma cells. (b) Confocal microscopic photographs of A549 and cisplatin-resistant A549/DDP cells cultured with Pt NCs-based chemotherapeutic agent (red fluorescence) after incubated for $4 \mathrm{~h}$, respectively. DAPI stained cell nuclei (blue fluorescence), and the scale bar is $50 \mu \mathrm{m}$ (reprinted with permission from [187], Copyright 2019, Elsevier).

avoiding the usage of additional reducing agents [74]. The reduction mechanism is due to the energy transfer under the condition of light irradiation to generate the reductive hydration electrons or reactive radicals [63], which is frequently utilized to explore the origination of photoluminescence because no other compounds are introduced. The Pt NCs with the size ranged from 1.0 to $2.2 \mathrm{~nm}$ were prepared with the aid of UV light under the alkaline environment [75]. The presynthesized NCs have a face-centred cubic spatial structure, and the author inferred that the UV light could achieve the nucleation and growth of NCs, not by the thermal reduction. Finally, electrodeposition is a usual and effective method to control size and shape of metals and decorate the substrate surface by adjusting deposition parameters, involving a plenty of distinct advantages such as low cost, rapid producing rates, and precious controllability [76, 77]. Qian et al. firstly modified the four-generation poly(amidoamine) dendrimer $\left(\mathrm{G} 4-\mathrm{NH}_{2}\right)$ onto indium-doped tin oxide (ITO) and then electrodeposited Pt NCs on the surface of G4- $\mathrm{NH}_{2}$ dendrimer to form larger-sized NPs near $100 \pm 20$ $\mathrm{nm}$ [78]. The size and morphology could be tailored by polyelectrolytes or the types of PAMAM ligands. These physicochemical techniques mentioned above are environmentally friendly, less time-consuming, and convenient, which are beneficial to investigate the formation process and fluorescence mechanism and meet the demand of green industrial fabrication.

In addition, the defined templates during the formation of Pt NCs can be extended to a broad range involving multicomponent materials like multimetallic alloy [79-83] and 

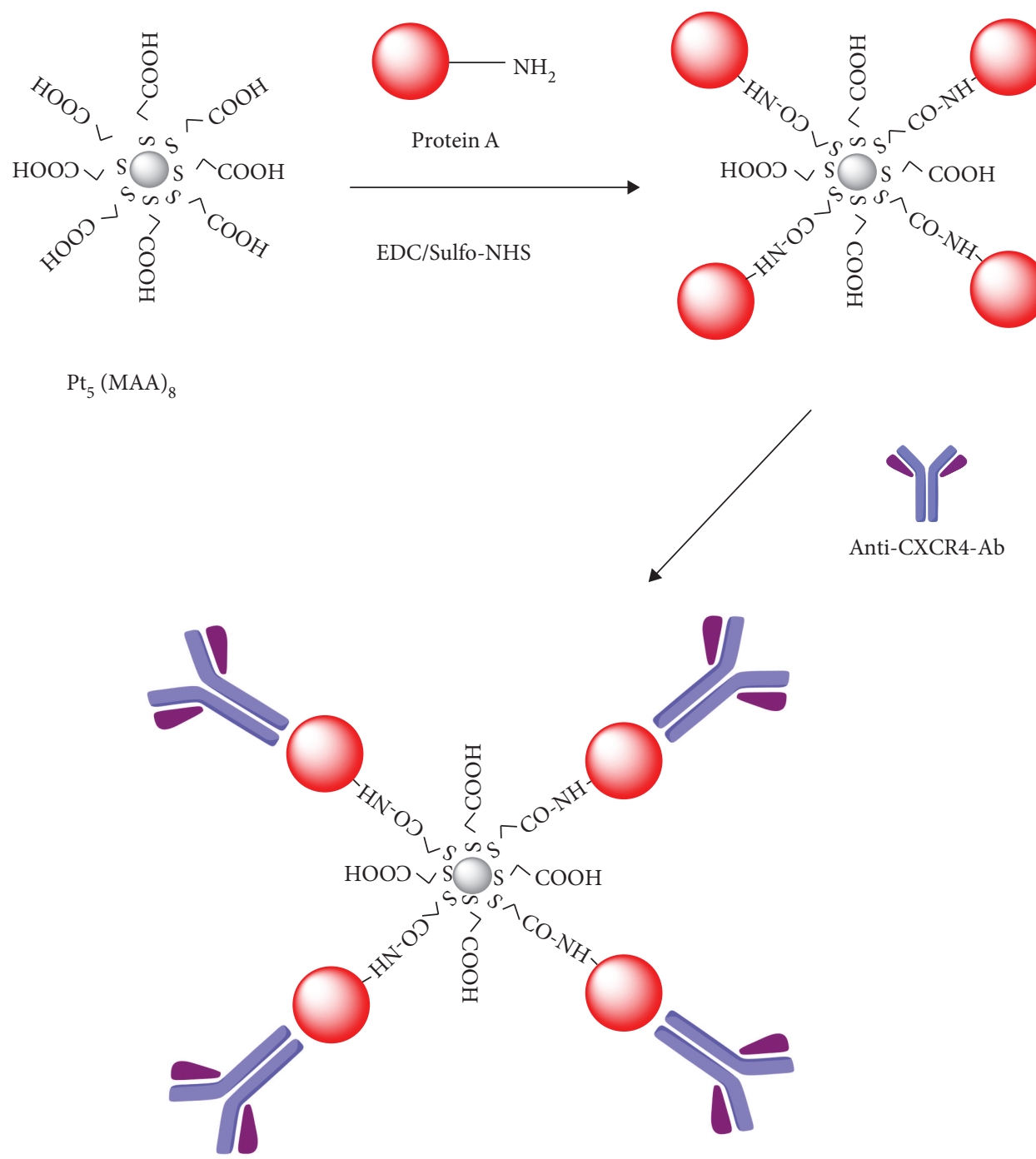

(a)

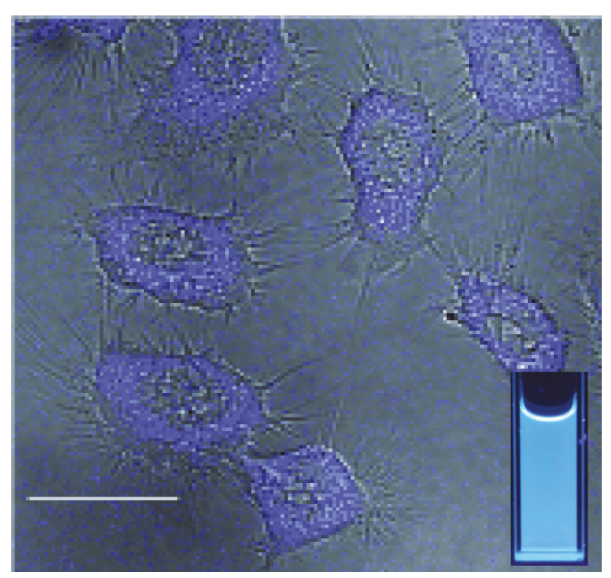

(b)

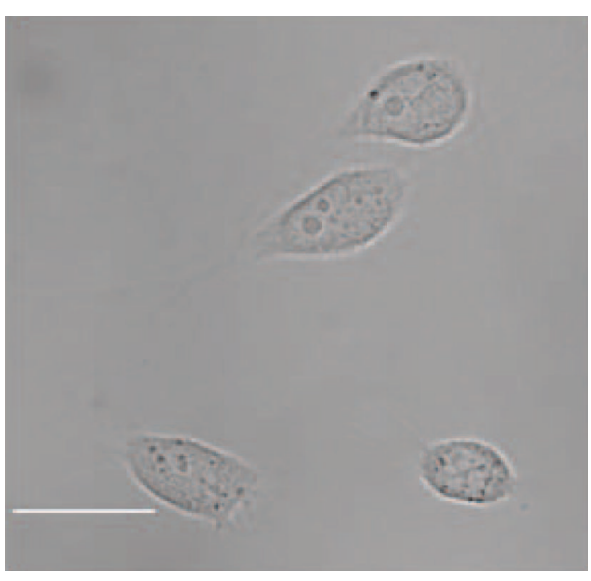

(c)

Figure 9: (a) The schematic fabrication of $\mathrm{Pt}_{5}(\mathrm{MAA})_{8}$-protein A-anti-CXCR4-Ab complex. Confocal microscopic photographs merged with differential interference contrast (DIC) picture of (b) HeLa cells and (c) CHO-K1 cells stained by a blue fluorescent antibody-modified Pt complex. The scale bars are $20 \mu \mathrm{m}$ (reprinted major modification with permission from [130], Copyright 2011, Wiley). 


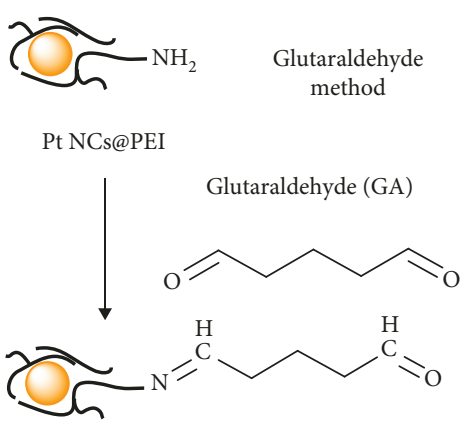

Pt NCs@PEI-GA

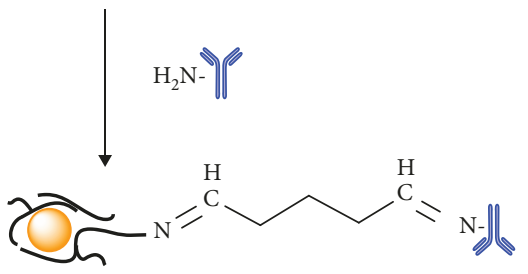

Pt NCs@PEI-(anti-CXCR4-Ab)
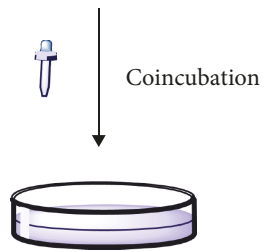

HeLa cells

: Pt NCs

$\mathrm{H}_{2} \mathrm{~N}-1 /$ : antibody

: culture dish

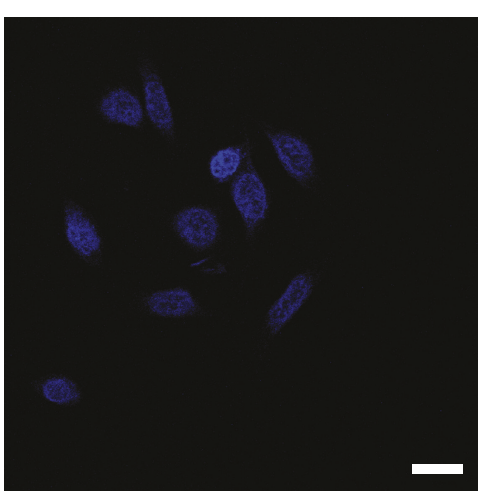

(b)

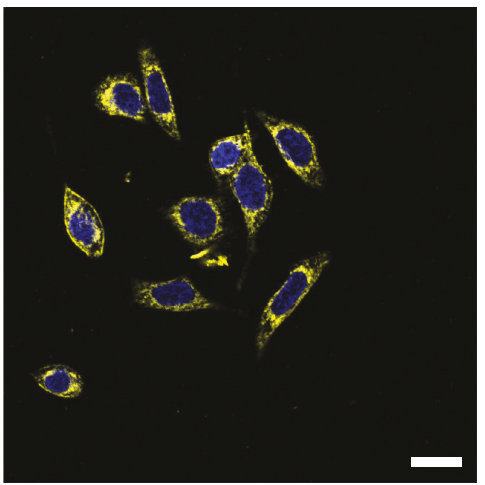

(d)

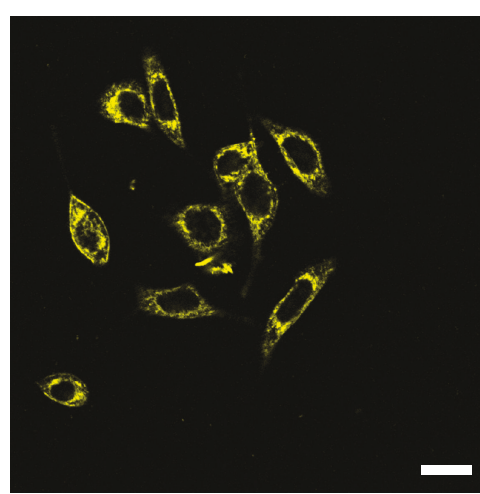

(c)

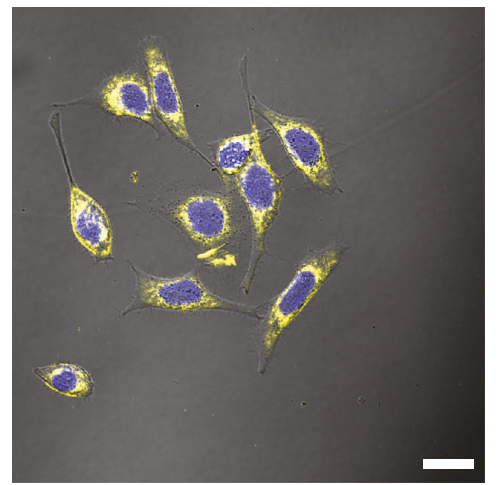

(e)

(a)

Figure 10: (a) The schematic synthesis of Pt NCs@PEI conjugated with the antibody by a glutaraldehyde method. Confocal microscopic photographs merged with differential interference contrast (DIC) picture of HeLa cells stained by (b) only DAPI, (c) only Pt NCsantibody complex, (d) merge of (b) and (c), and (e) the bright filed of (d). The scale bars are $20 \mu \mathrm{m}$ (reprinted major modification with permission from [188], Copyright 2016, Royal Society of Chemistry).

doped substrate material [84-87]. For instance, bimetallic or multimetallic alloy is designed by a combination concept of different metallic compounds in order to obtain composite performance. Pure Al, Co, and Pt were melted and then dealloyed in alkaline solution at certain temperature to form $\mathrm{Al}_{85} \mathrm{Co}_{14} \mathrm{Pt}_{1}$ ternary alloy [88]. Even the amount of $\mathrm{Pt}$ was quite small, the electrocatalytical activity was improved dramatically and the ampere-metric determination limit of sodium nitrite $\left(\mathrm{NaNO}_{2}\right)$ was $0.067 \mu \mathrm{M}(S / N=3)$. On the other hand, a doped substrate method is allowing Pt NCs doped or dispersed into the substrate materials such as polymer film [89-92], inorganic substrate [93-96], metal organic framework (MOF) [97], carbon nanotubes (CNTs) [98, 99], and graphene [100-102], which could easily adjust and enhance the pure NCs' chemical and physical performance. Pt NCs with an average diameter of $0.7 \pm 0.3 \mathrm{~nm}$ were deposited on $\mathrm{SmMn}_{2} \mathrm{O}_{5}$ (SMO) mullite-type oxides by an atomic layer deposition method (ALD), showing the efficient ability to solve the CO poisoning problem for the Pt-based catalyst
[103]. This catalytic activity even under low temperature originated from $\mathrm{O}_{2}$ dissociation at the bifunctional interface structure. Lee et al. put forward that monodispersed Pt NCs (diameter $=1.25 \pm 0.30 \mathrm{~nm}$ ) were loaded onto threedimensional graphene-like carbon (3D GLC) which was employed in the electrochemical oxidation reaction [104]. These Pt NCs-doped 3D GLC catalysts possess near 2910 $\mathrm{m}^{2} / \mathrm{g}$ superficial area and exhibit excellent glycerol oxidation reaction (GOR) activity and extreme stability via firm adhesion of glycerol on the Pt NCs' surface. Recently, Pt precursor solution was added into poly(diallyldimethylammonium chloride) and poly(sodium 4-styrenesulfonate) to assemble polyelectrolyte multilayer (PEM) films and then the Pt NCs were in situ yielded with various sizes from 1.2 to $2.3 \mathrm{~nm}$ only by tailoring the salt concentration and reduction time, instead of the reduction temperature [105].

2.2. Template-Free Method. Template-free protocol is a method avoiding the introduction of extra substance and 


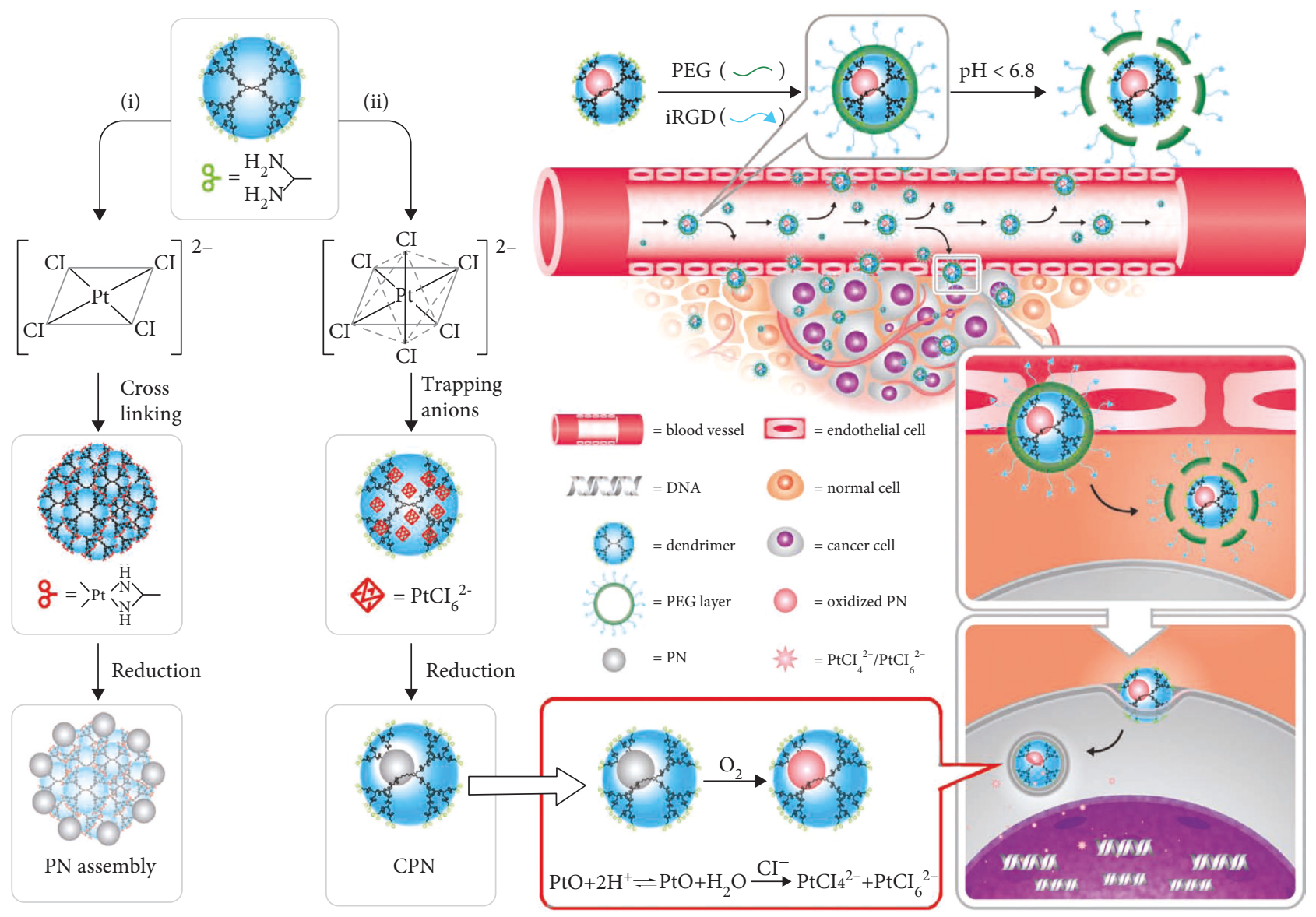

(a)
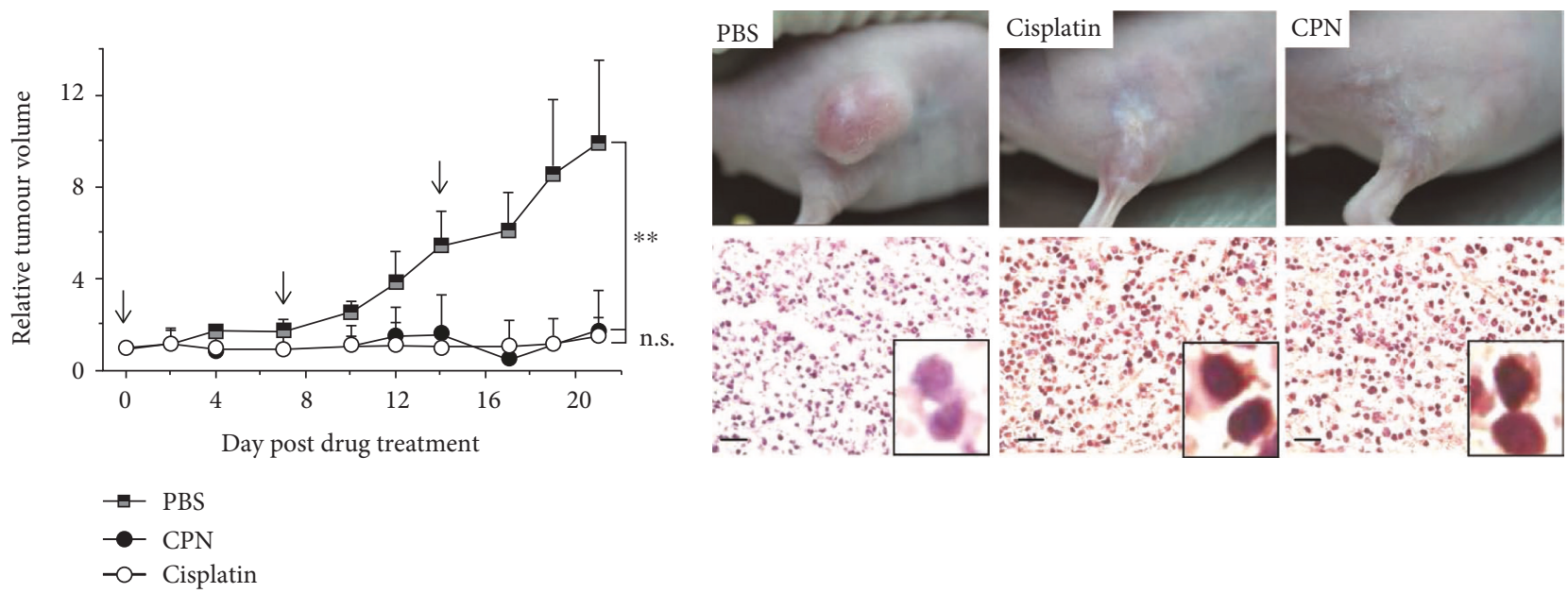

(b)

Figure 11: Continued. 

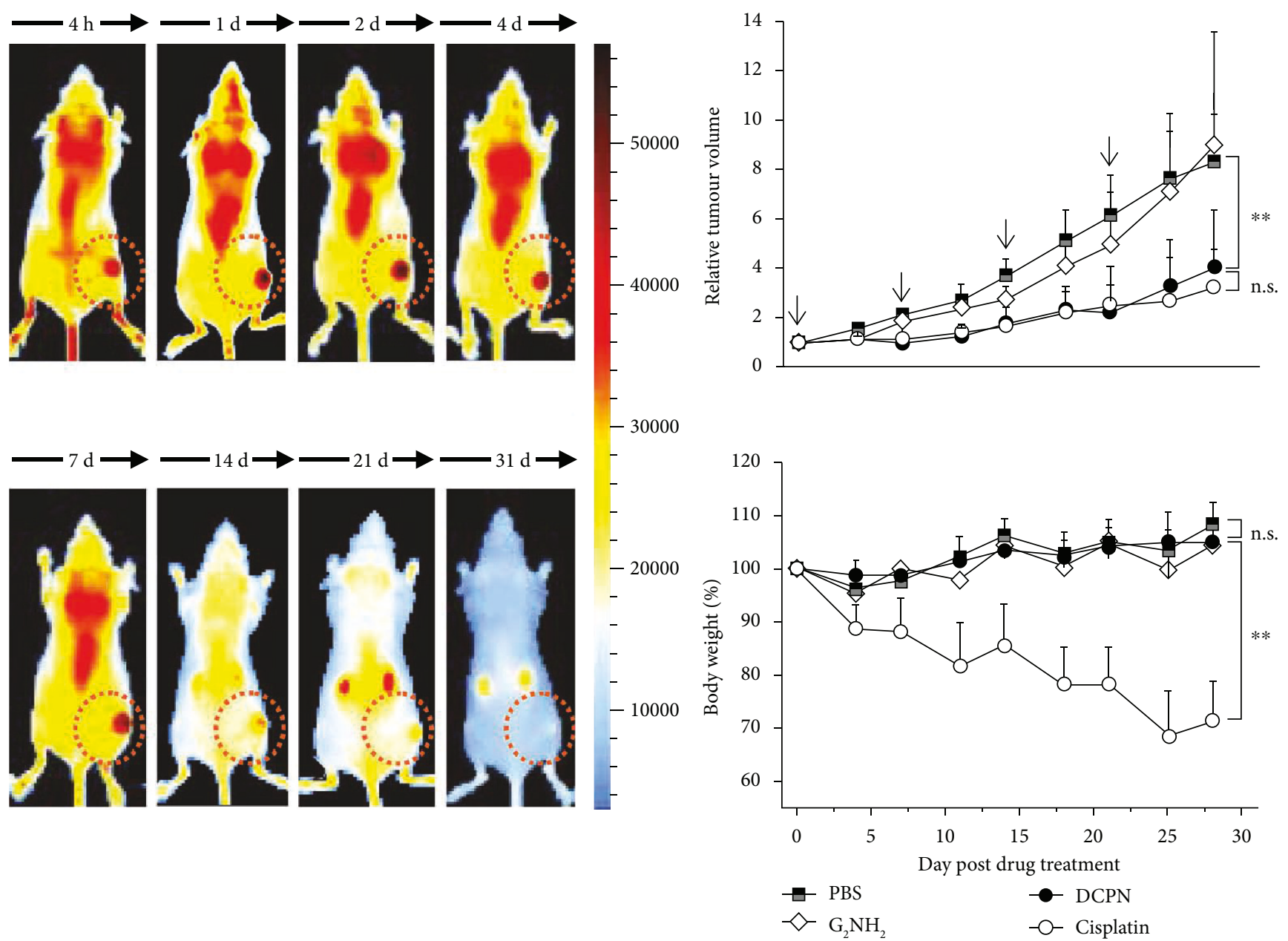

(c)

Figure 11: (a) Schematic route of fabricating caged Pt NCs (CPN) and the endocytosis pathway of CPN after conjugated with a tumourpenetrating peptide and PEG corona to form double-caged Pt NCs (DCPN). (b) Relative tumour volume and photographs of tumour size at the end point; the apoptotic cell death was detected by TUNEL assay after treated by CPN, and the scale bar is $20 \mu \mathrm{m}$. (c) Tumour target imaging, relative tumour volume, and body weight of mice after IT and IV injection by DCPN (reprinted major modification with permission from [201], Copyright 2013, Wiley).

has extensive advantages such as effortless postprocessing and pure product [106]. Kawasaki's group proposed a surfactant-free synthetic approach to obtain Pt NCs consisting of 4 to 6 atoms with blue fluorescence in N,N-dimethylformamide (DMF) solution [107]. These NCs showed extreme stability against strong ionic and variable acid-alkali conditions. Subsequently, Duchesne and Zhang employed X-ray absorption near-edge spectroscopy (XANES) and extended X-ray absorption fine structure (EXAFS) techniques which revealed the details of surfactant-free-synthesized Pt NCs' local structure and oxidation states [108]. The local structure of Pt is primarily due to the changes in the metal-ligand coordination, not the Pt-Pt bonding. The oxidation of Pt species is a combination of $\mathrm{Pt}(\mathrm{IV})$ and $\mathrm{Pt}(0)$, indicating that nonmetallic Pt NCs are responsible for their fluorescent properties. Meanwhile, this surfactant-free method synthesized Pt NCs were used to sensitively sense the aqueous $\mathrm{Fe}^{3+}$ ion solution and the limit of detection was $4 \mathrm{ppm}$
$(15 \mu \mathrm{M})$ under the concentration range of $\mathrm{Fe}^{3+}$ ions from 0.007 to $0.530 \mathrm{mM}[109]$.

\section{Properties of Platinum Nanoclusters}

The properties of Pt NCs are the consequence of their distinct electronic and structural properties, which have access to NC's size, morphology, and surface surroundings inseparably. Herein, we summarize the classical features of Pt NCs including optical properties, catalytic properties, and other properties.

3.1. Optical Properties. Optical properties benefit for offering an insight to understand the electronic and geometric structures of M NCs in depth [110]. The applications of M NCs strongly depend on their optical properties, and there are a lot of research reported the NCs' unique optical phenomenon such as steady-state absorption and fluorescence, temperature-dependent fluorescence, ultrafast fluorescence 


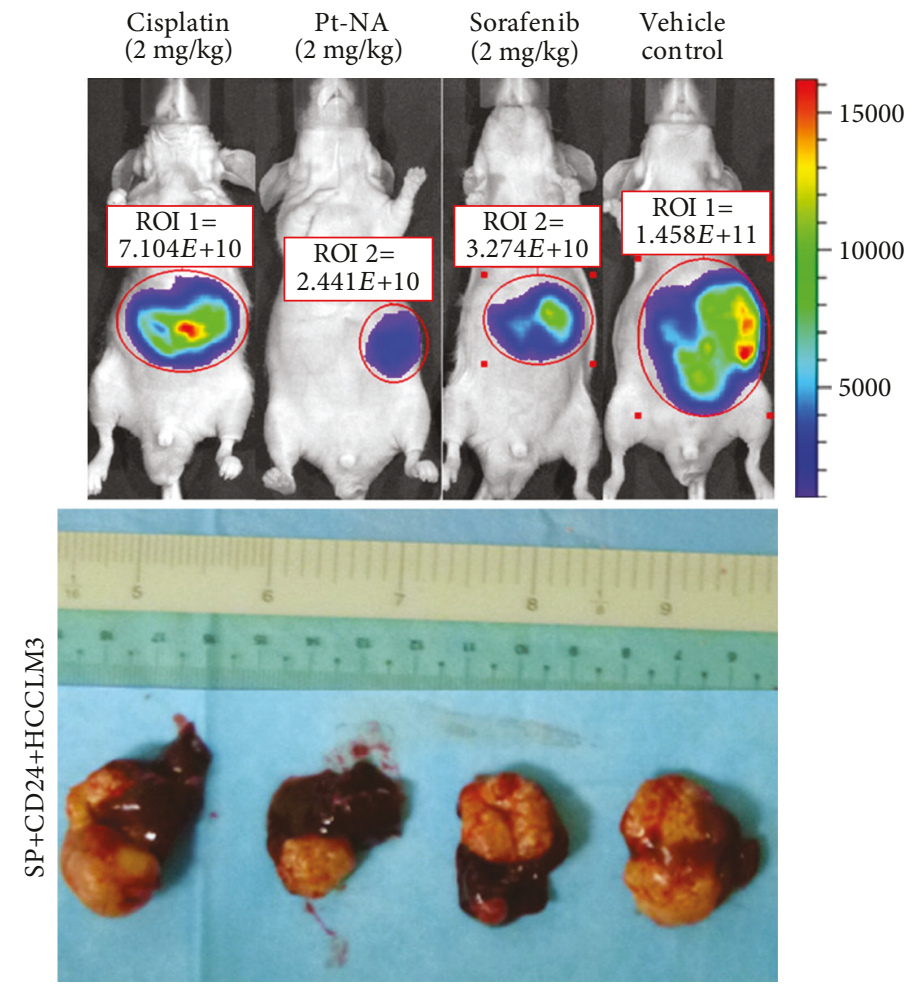

(a)

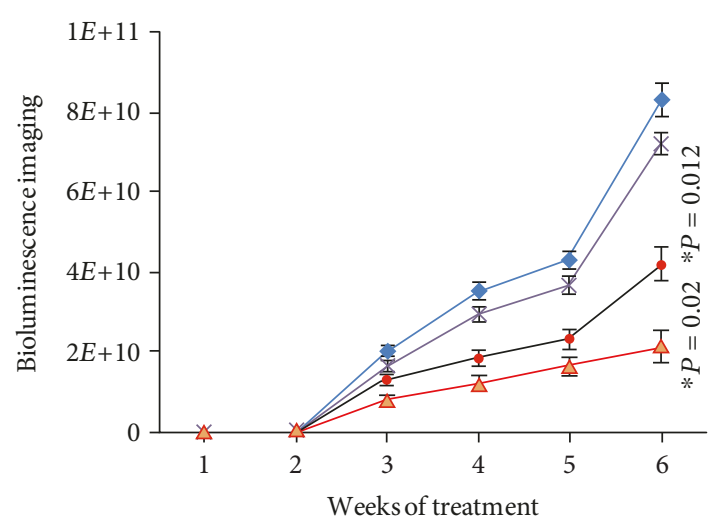

$\multimap$ Vehicle control $\triangle$ Pt-NA

$\longrightarrow$ Sorafenib $\quad \leftarrow$ Cisplatin

(b)

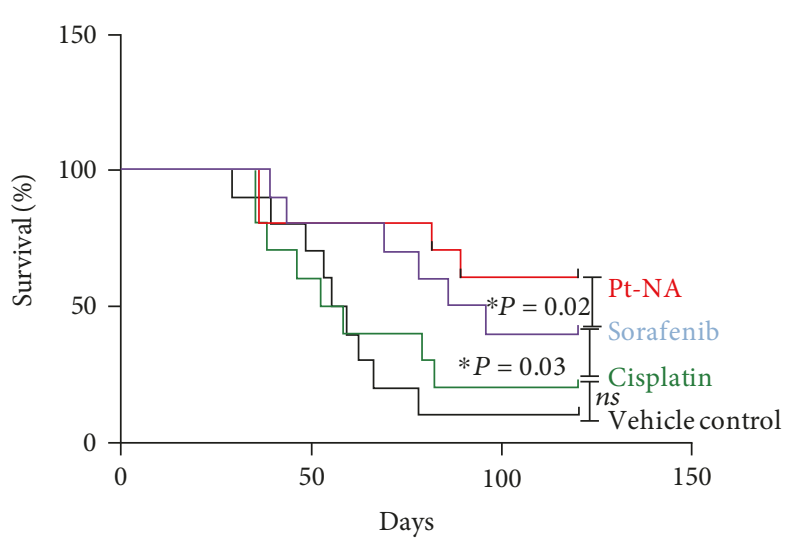

(c)

Figure 12: Continued. 


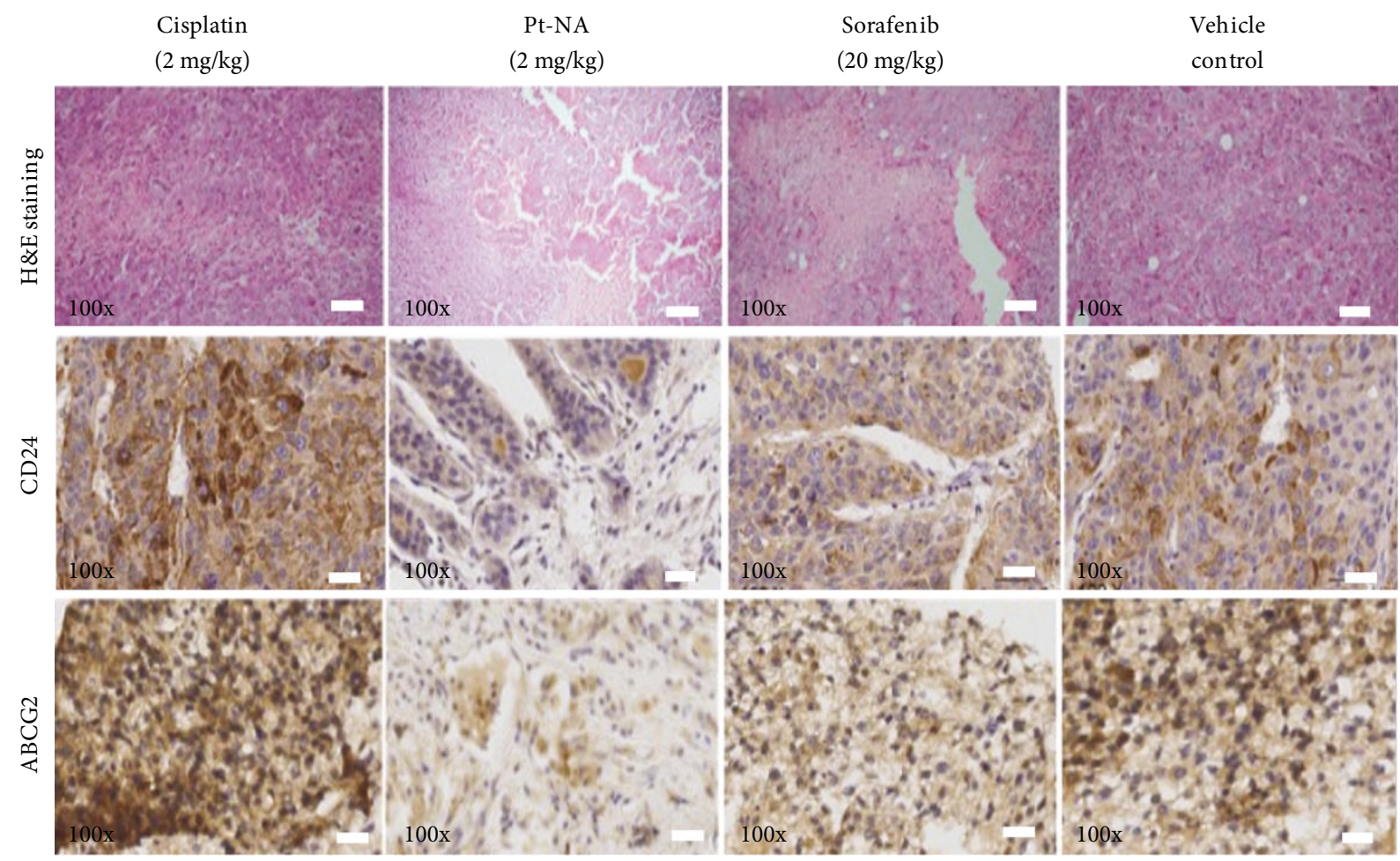

(d)

FIGURE 12: (a) Photographs of luminescence signals and the tumour-bearing livers of orthotopic tumour xenografts at the therapeutic end point for four treatment groups. The variation of (b) luminescence signals and (c) survival percentage of mice versus the time increasing. (d) Immunohistochemical staining for the expression of ABCG2 and CD24 in the tumours in four treatment groups; the scale bar is $100 \mu \mathrm{m}$ (reprinted with permission from [203], Copyright 2016, American Chemical Society).

and transient absorption, fluorescence enhancement, and electrochemiluminescence [21, 111-113]. This part, we will introduce about the theoretical and practical progress of size-dependent fluorescence for Pt NCs.

Unlike M NPs which possess apparent surface plasmon resonance (SPR) absorption, Pt NCs lost this particular property, replaced by the size-dependent fluorescence ranging from the visible to near-infrared (NIR) region. Generally, this fluorescence of Pt NCs generated from the electronic transitions between the highest occupied molecular orbital (HOMO) and lowest unoccupied molecular orbital (LUMO). Their finite size is a critical point for molecule-like electronic transitions between HOMO and LUMO energy levels. Energy transitions can be expressed as Equation (1) based on the jellium model $[3,114]$ :

$$
E_{\delta}=\frac{E_{f}}{N^{1 / 3}}
$$

where $E_{\delta}$ represents the energy level spacing, $E_{f}$ is the Fermi energy, and $N$ stands for the number of atoms in NCs. The $E_{f}$ of free electron is only related to the metals' Wigner-Seitz radius $\left(r_{s}\right)$ or the electron density $\left(\rho_{0}\right)$ because the free electrons are piled up with constant electron density. Owing to $N$ equals to $\left(R / r_{s}\right)^{3}$, Equation (1) transfers to Equation (2) using the emission/excitation frequency $\left(\omega_{0}\right)$ and NCs' radius
$(R)$ expressed as follows:

$$
E_{\delta}=\hbar \omega_{0}=\frac{E_{f} r_{s}}{R} .
$$

Equation (2) is suitable for the M NCs when $N$ is smaller than 20 , which is well depicted by a spherical harmonic potential. Hamiltonian for an electron in a single-particle 3D harmonic oscillator can be described as follows:

$$
H=-\frac{p^{2}}{2 m}+\frac{m \omega_{0}^{2} q^{2}}{2}
$$

where $p$ represents the single-electron momentum and $q$ is the coordinate operators. The small anharmonic distortion term should be taken into consideration under the condition of $N>20$. Defining the distortion parameter $(U)$ as a constant value (0.033), the correlated transition energy spacing $\left(\Delta E_{e m}\right)$ is shown as Equation (4) using angular momentum $(l)$ and shell number $(n)$ expressed as follows:

$$
\Delta E_{e m}=\frac{E_{f}}{N^{1 / 3}}\left[1-U\left(l_{e}^{2}-l_{g}^{2}-\frac{n+2}{3}\right)\right],
$$

where $l_{e}$ represents the angular momentum of excited state and $l_{g}$ is the angular momentum of ground state. Based on the Equations $(2)(N<20)$ and $(4)(N>20)$ displayed above, 


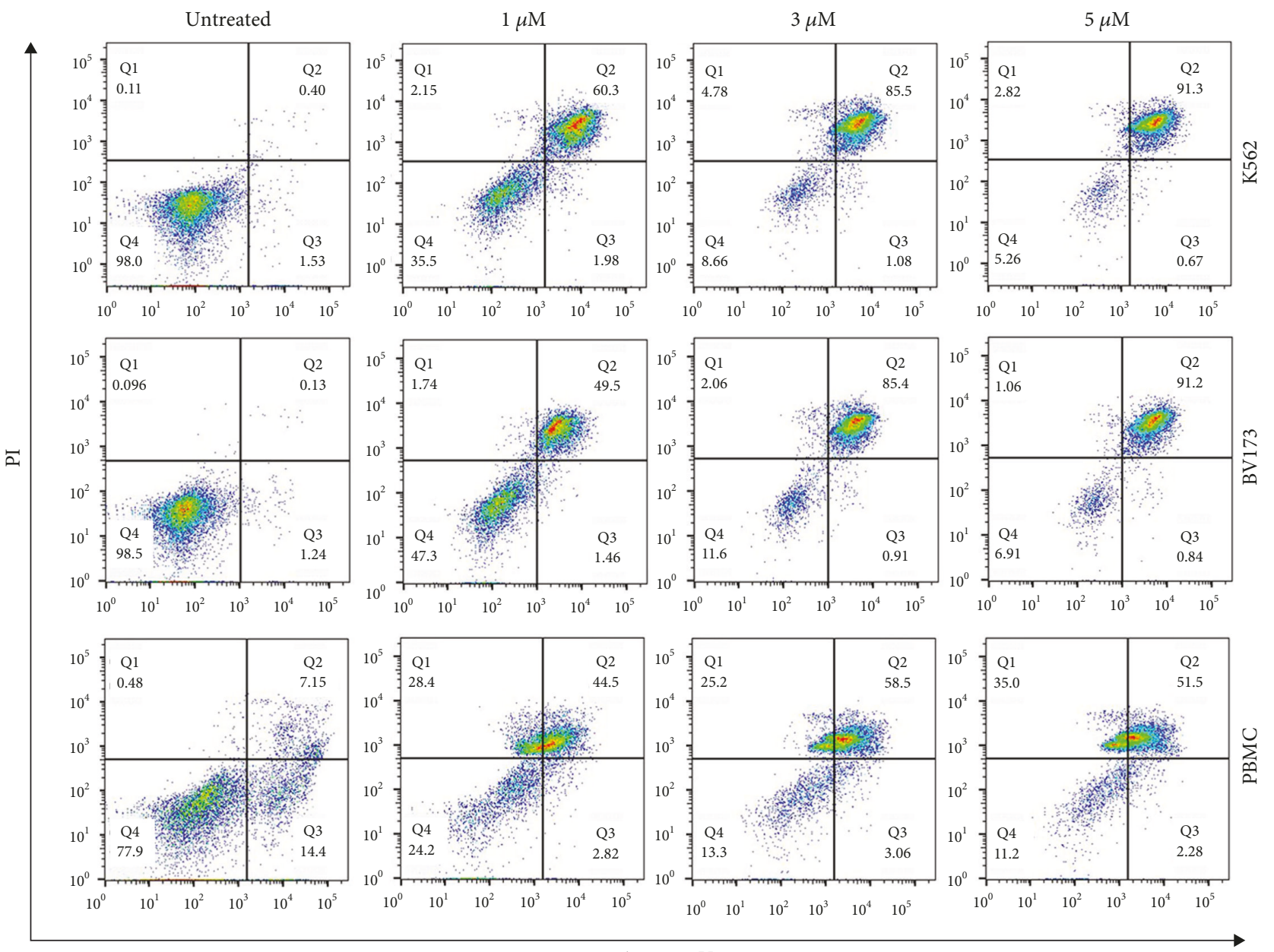

Annexin V

(a)

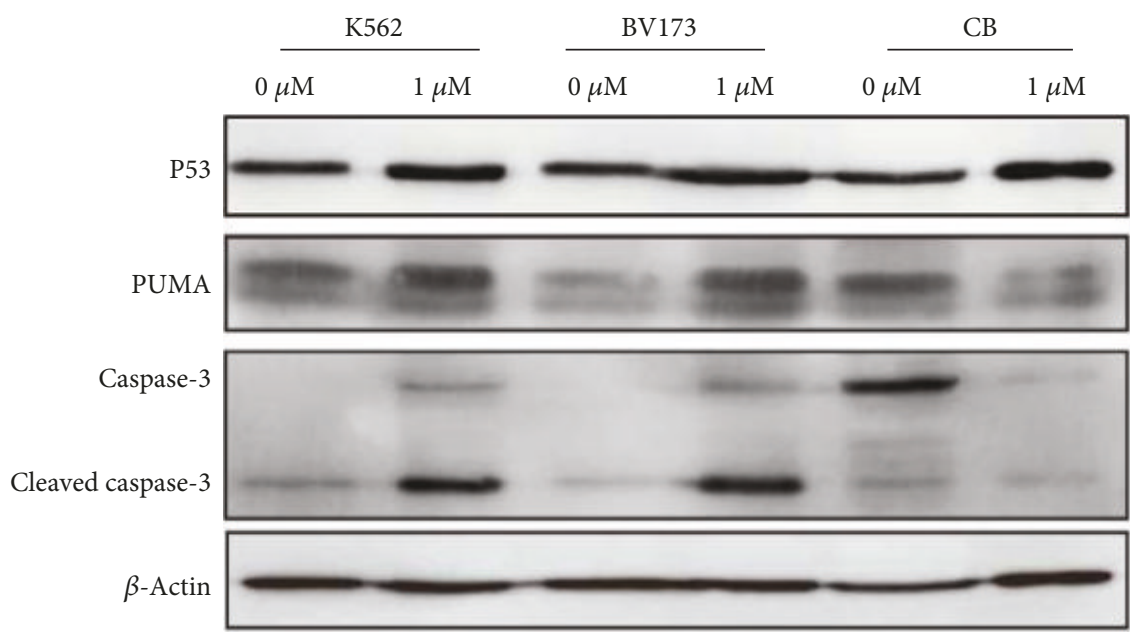

(b)

FIgUre 13: (a) The apoptosis in hematopoietic K562 and BV173 cancer cells and hematopoietic normal cell (PBMCs) induced by Pt NCsbased anticancer drugs after cultured for $4 \mathrm{~h}$. (d) The west blotting assay result of three kinds of cells to detect protein expression of p53, PUMA, caspase-3, cleaved caspase-3, and $\beta$-actin, respectively (reprinted with permission from [186], Copyright 2018, Elsevier).

this dependency can be defined as the large size of M NCs is related to the small energy level spacing with longer emission wavelength fluorescence emitted and vice versa (Figure 4(a)).
Besides of the size-dependent fluorescence effect described above, surrounding ligands or templates also play a significant role on the fluorescent properties through ligand-metal charge 


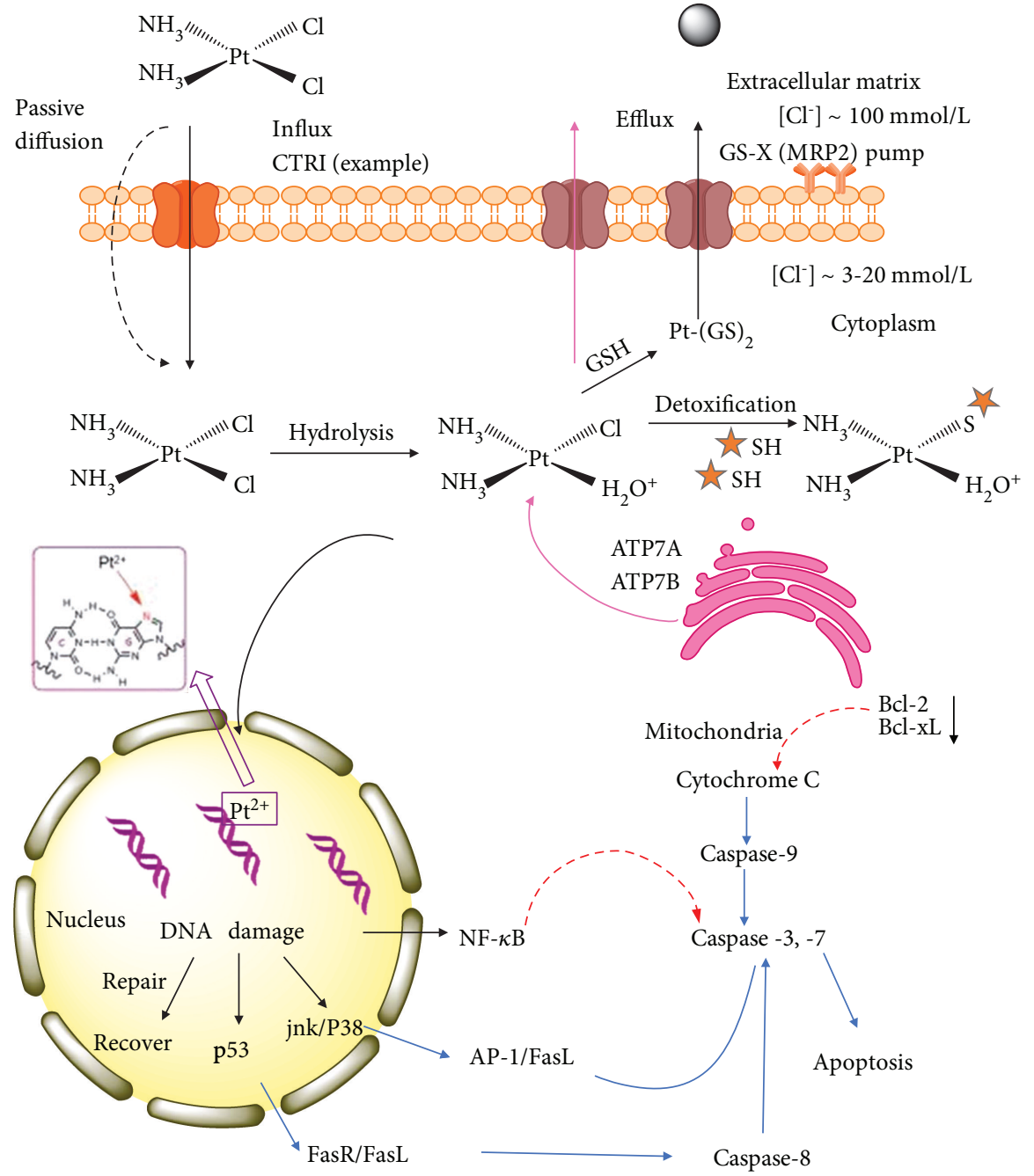

(a)

Figure 14: Continued. 


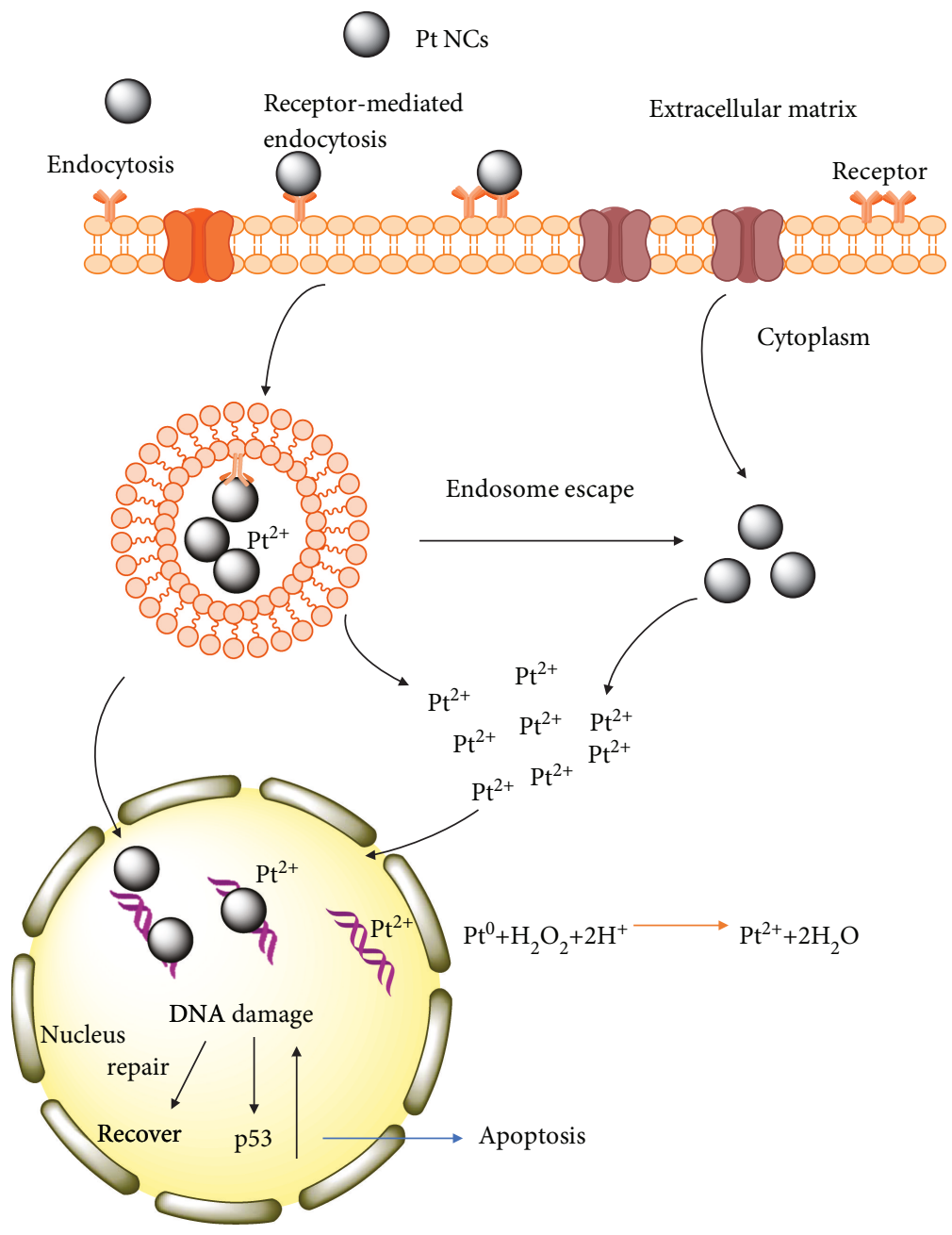

(b)

Figure 14: (a) Schematic apoptosis mechanism of cisplatin and inhibiting cisplatin-induced apoptosis. Red dotted line means that antiapoptotic factors counteract caspase activation. (b) Schematic apoptosis mechanism of Pt NCs. Abundant oxidized Pt ions and Pt NCs coordinate the DNA damage activating the p53 pathway (reprinted with permission from [204], Copyright 2017, Elsevier).

transfer (LMCT) (Figure 4(b)) [115-118]. Not only the enhancement or quenching of fluorescence could be realized by the collaboration between NCs and ligands but also the fluorescent intensity and maximum peak of emission wavelength can be adjusted. Thus, the mechanism of M NCs' fluorescence is ascribed to the intrinsic electronic transitions between HOMO-LUMO energy levels and the electronic transitions between NCs' surface and surrounding ligands via LMCT.

Until now, fluorescent Au and Ag NCs have been deeply researched and utilized in various fields [119-125]. As for the fluorescent Pt NCs, the number of synthetic methods, usable templates, and optical applications is significantly fewer than $\mathrm{Au}$ or Ag counterparts and most reports focused on the blue-, green-, and yellow-emitting fluorescence (Figure 5). The longer emission wavelength, especially near-infrared (NIR) region, is rarely mentioned. NIR fluorescence has a plenty of merits such as easy detection, less autofluorescence interference, and more use safety, making it attractive in both biological sensing and labelling analysis [126]. Furthermore, the fluorescent Pt NCs have the specific advantage than Ag and $\mathrm{Au}$ NCs, such as higher photoluminescence quantum yield (QY) and instinct properties like anticancer [127]. Therefore, great efforts payed out to study on the facile and repeatable synthesis of fluorescent Pt NCs with longer emission wavelength in the past decades.

Bovine serum albumin (BSA) supported blue fluorescent Pt NCs (emission wavelength region from 350 to $500 \mathrm{~nm}$ ) which were fabricated by an easy $\mathrm{NaBH}_{4}$-reduced method. These NCs could achieve the selective examination of hypochlorite among the concentration range from 12 to $240 \mathrm{mM}$ via the visible fluorescence quenching due to the formation of oxidized Pt [128]. A GSH-induced etching process were employed to produce the yellow fluorescent $\mathrm{Pt}$ NCs (maximum emission wavelength at $570 \mathrm{~nm}$ ) with the fluorescent QY at 17\% [129]. Most Pt NCs are in the $\mathrm{Pt}(\mathrm{I})$ state, and the optimized molar ratio between $\mathrm{Pt}$ and GSH is determined at $1: 10$. Afterwards, blue [130] and green [131] fluorescent Pt NCs were precisely synthesized by employing the template of fourthgeneration polyamidoamine dendrimer, short for PAMAM $(\mathrm{G} 4-\mathrm{OH})$, and their absolute QYs reach to $18 \%$ and $28 \%$ 


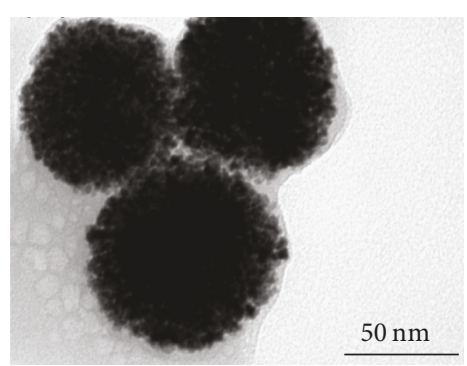

(a)

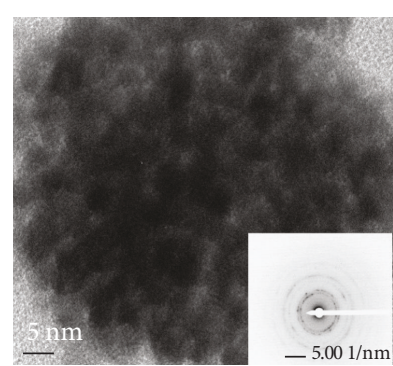

(b)

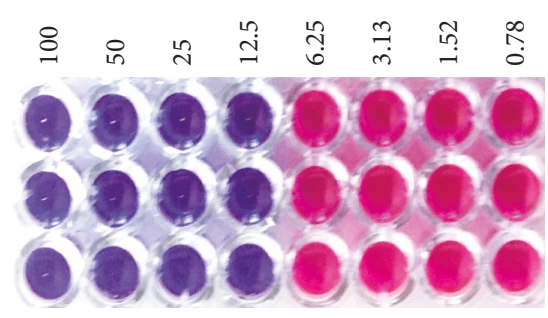

(c)

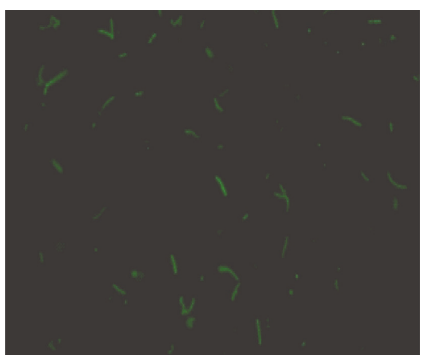

(e)

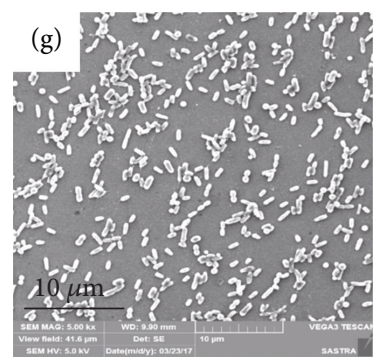

(g)

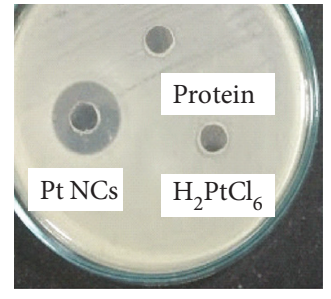

(d)

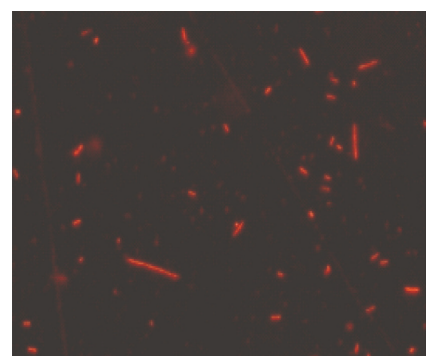

(f)

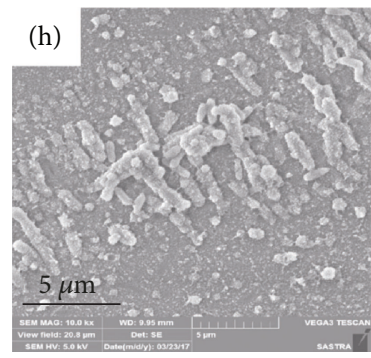

(h)

FIGURE 15: (a) TEM photograph of Pt NCs; the scale bar is $50 \mathrm{~nm}$. (b) HR-TEM photograph shows that the NCs are formed via self-assembled NPs (scale bar is $5 \mathrm{~nm}$ ). Inset corresponds the selected area electron diffraction (SAED) pattern. (c) MIC determination by resazurin microtiter plate assay (REMA) for Pt NCs towards Salmonella typhi and (d) zone of inhibition assay at MIC (12.5 $\mu \mathrm{M})$. Fluorescence microscopy photographs of Salmonella typhi double stained with acridine orange (AO, membrane, green) and propidium iodide (PI, nucleic acid, red) for (e) untreated cells and (f) $12.5 \mu \mathrm{M}$ Pt NCs treated. SEM photographs of (g) untreated cells and (h) $12.5 \mu \mathrm{M}$ Pt NCs treated (reprinted major modification with permission from [206], Copyright 2018, Elsevier).

in water, respectively. We previously reported that various aqueous $\mathrm{Pt}$ NCs from blue to yellow fluorescence were prepared by a facile method using hyperbranched polyethyleneimine (PEI) as a stabilizing agent and environment-friendly L-ascorbic acid as a reductant [132]. Their optical properties can be tailored by adjusting the molar ratio between $\mathrm{Pt}$ ions and protecting ligands. Moreover, these Pt NCs have the ability of quantitative and selective detection for $\mathrm{Co}^{2+}$ ions and the limit of detection is up to $500 \mathrm{nM}$. Meanwhile, $\mathrm{Xu}$ et al. used the same method to prepared blue fluorescent Pt NCs and applied them for sensing nitroimidazoles (MTZ) with the limit concentration of $0.1 \mu \mathrm{M}$ [133]. As for longer fluorescent emission, García's group demonstrated that red fluorescent Pt NCs in aqueous solution could be obtained by a chemical reduction method using lipoic acid (LA) as a capping agent [134]. The synthesized NCs with the maximum emission wavelength at $680 \mathrm{~nm}$ have a relatively high QY at $47 \%$ and present excellent stability towards $\mathrm{pH}$ media and high ionic solution. Moreover, hemoglobinprotected $\mathrm{Pt}$ NCs appeared to have two fluorescence regions: emission wavelength at $450 \mathrm{~nm}$ which is contributed by $\mathrm{Pt}_{6} \mathrm{NCs}$ at zero oxidation state and emission wavelength at $760 \mathrm{~nm}$ that is due to the formation of aggregated 
$\mathrm{Pt}(\mathrm{II})-\mathrm{Hb}$ complexes caused by LMCT effect from N/O to $\mathrm{Pt}$ atoms (the structure is assigned to $\mathrm{Pt}_{16} \mathrm{NCs}$ ) [135]. They also indicated that the NIR fluorescence is too weak to observe clearly because of a lower proportion of $\mathrm{Pt}$ (II) on the NC's surface (only near 13.68\%). To our knowledge, it is the longest emission fluorescence reported for Pt NC materials, even for their poor fluorescent intensity.

In spite of the progress discussed above, the synthesis of fluorescent Pt NCs is still in its initial stage. There remains some challenge that needs to be solved, including the acquisition of highly longer emission fluorescent Pt NCs to realize the practice application, clarification of fluorescent mechanism to provide guidance, and large-scale production of $\mathrm{Pt}$ NCs to meet industrial demand.

3.2. Catalytic Properties. M NCs have been widely investigated for their catalytic properties from the theory to practical application [32, 136, 137]. Pt-based catalysts are pervasively applied in the development of the cost-effective proton exchange membrane fuel cells (PEMFCs) involving electrochimerical oxygen reduction reaction (ORR), methanol oxidation reaction (MOR), ethanol oxidation reaction (EOR) [138-142], and the catalysis of different chemical reactions like hydrogenation reactions [143-146]. It is well known that the catalytic reactivity of $\mathrm{Pt}$ varies by their sizes, morphology, and dispersion [147].

There are two common views for Pt-based catalysts. One is that Pt NPs (near $2 \mathrm{~nm}$ ) are thought to be at the limit of their catalytic performance due to too strong Pt-O binding energy on the smaller clusters [148, 149]. That is to say, large Pt NPs with a face-centred-cubic (FCC) structure (near 2 to $3 \mathrm{~nm}$ ) have the best activity and the ultrasmall Pt NCs are considered to have lower or even no catalytic ability, especially for ORR. However, a recent study rejected this traditional concept and their applicability [150]. It was found that Pt NCs with the size less than $2 \mathrm{~nm}$ also emerged a better catalytic performance. Accordingly, the catalytic capacity is no longer dependent on the size effect. Vajda et al. proved that small $\mathrm{Pt}_{8-10} \mathrm{NCs}$ loaded on a high-surface area template showed 40-100 times higher catalytic activity for the oxidative dehydrogenation than common Pt-based catalysts and extreme selectivity to produce the propylene [151]. Considering about the hydrogenation of methyl acrylate, the catalytic capacity of Pt-based materials depended on their size ranged from 2.4 to $3.0 \mathrm{~nm}$ which could be controlled by the amount of poly(N-vinyl-2-pyrrolidone) (PVP) [152]. Subsequently, Lan's group modified the counter electrode by PVPprotected Pt NCs for the dye-sensitized solar cell (DSSC) and found that this modified electrode exhibited light soaking durability and high conversion efficiency (near 9.37\%) in a highly volatile electrolyte system [153]. Based on the results above, the "uniqueness of size effect" issue for Ptbased catalysts is now reexamined and no longer exist.

The other common view is that certain morphology of $\mathrm{Pt}$ NCs like topological magic number structure (e.g., $\mathrm{Pt}_{13}$ and $\mathrm{Pt}_{55}$ ) with high symmetry could exhibit the higher catalytic ability $[148,154]$. Imaoka et al. compared the ORR catalytic capacity between $\mathrm{Pt}_{12}$ NCs with less symmetric structure prepared using a phenylazomethine dendrimer with a tetraphe- nylmethane core (DPA-TPM) and $\mathrm{Pt}_{13}$ NCs with high symmetry obtained using phenylazomethine dendrimer with a triphenylpyridylmethane core (DPA-PyTPM) (Figure 6) [155]. One interesting finding is that misshapen structure $\mathrm{Pt}_{12}$ has a double catalytic activity compared with that of the topological stable $\mathrm{Pt}_{13}$ with the high symmetry. This distinction is mainly caused by two reasons: (1) less symmetric structure of $\mathrm{Pt}_{12}$ with a smaller number of internal $\mathrm{Pt}-\mathrm{Pt}$ bonds and (2) structural transition of $\mathrm{Pt}_{12}$ makes the size further decreases against the smallest limit of icosahedral $\mathrm{Pt}_{13}$ NCs. Besides, this group further explored the atomicityspecific catalytic activity of Pt NCs within a significant small atomicity $(n<20)$, revealing $\mathrm{Pt}_{17}$ and $\mathrm{Pt}_{19}$ exhibited higher performance than other series [150]. As a result, the atomic coordination structure is completely different from that of the larger-sized FCC nanomaterial and the catalytic activities for the ORR are significantly altered by the spatial arrangement and atomicity. Hence, the fact discussed above proved the idea that the catalytic activity has weak access to the topological magic number of $\mathrm{Pt}$ on the nanoscale.

In summary, the emergence of Pt NCs has already reversed the traditional idea on Pt-based catalysts. The further investigations about the precise control of atomic number, seeking of different steric topological structures, and catalytic application of diverse chemical reactions need to be comprehensively and deeply studied in future.

3.3. Other Properties. Except for the optical and catalytic properties, Pt NCs also have unique physical characteristics, like thermal properties [156]. The phase stability of $\mathrm{Pt}_{\mathrm{n}}$ NCs ( $n=38,147,309$, and 561 atoms) under various temperature conditions was surveyed by the molecular dynamics (MD) simulation combined with an embedded atom scheme (EAM) [157]. Furthermore, Akbarzadeh and Parsafar discussed the melting and thermal physical properties of $\mathrm{Pt}_{\mathrm{n}}$ NCs in a larger size ( $n=256$ to 8788 atoms) by means of molecular dynamics simulations employing quantum Sutton-Chen (QSC) potential [158]. Both for the larger and relative smaller $\mathrm{NCs}$, the melting temperature goes up as the NCs' size increased and that of $\mathrm{Pt}_{8788} \mathrm{NCs}$ approaches to the Pt bulk limit.

\section{Biological Applications of Platinum Nanoclusters}

Pt NCs consisting of few to tens of atoms own plenty of outstanding features and possess a great potential in the various applications, e.g., catalysis [159], sensing [133], and cancer therapy [160]. This part, we focus on the Pt NCs' biological applications which are strongly in accordance with their size-dependent effects and the coordination between NCs and functional surrounding ligands.

4.1. Biological Imaging. In the past decades, fluorescent biological imaging technology which is the process of light emission in living organisms [161] became an indispensable and visualized tool for the drug delivery system $[162,163]$, gene therapy [164], and cancer diagnoses [165, 166]. The used fluorophore is a key point for successful bioimaging of cells, 
which concerns about their safety, sensitivity, and wide applicability. Organic dyes [167-169], semiconductor quantum dots (QDots) [170, 171], fluorescent proteins [172, 173], lanthanides [174, 175], and carbon dots (CDots) [176, 177] as the common fluorophores have been already explored for practical imaging and extensively presented their merits and drawbacks. For example, organic dyes possess the high fluorescence QY; however, the dramatic cytotoxicity severely handicaps their practical applications [178]. Besides, QDots have unique features such as tunable colours, great photostability, narrow emission spectra, and broad excitation spectra [179]. The disadvantages like large size $(>3 \mathrm{~nm})$, on-and-off blinking behaviour, and low biocompatibility are important issues that need to be solved [180, 181]. As an alternative to organic dyes and QDots, M NCs have a crowd of strike features like ultrasmall size, water solubility, high fluorescent efficiency, large Stokes shifts, excellent photostability, and low cytotoxicity [182], making them become the safe and nontoxic clinical fluorescent contrast agents. In comparison to well-studied Au and Ag NCs [31, 183-185], relatively little research investigated the bioimaging application of fluorescent Pt NCs. In general, the imaging way of Pt NCs can be divided into two parts: (1) direct labelling without any other materials and (2) combination of certain biomolecule (e.g., proteins and DNA) to targeted imaging. Our previous work reported that fluorescent $\mathrm{Pt}$ NCs stabilized by polyamine ligands (average size near $1.4 \mathrm{~nm}$ ) could accomplish the biostaining of the suspension hematopoietic cell system [186]. The ligand-capped Pt NCs could selectively enter into K562 and BV173 cancer cells compared to the normal peripheral blood mononucleated cells (PBMCs) from healthy donors (Figure 7). This distinction gives an opportunity to achieve the specific labelling of hematopoietic cells during the disease diagnosis. Recently, we extended this fluorescent probe to label the lung cancer [187]. The classical human lung adenocarcinoma cells were chosen to examine their biological imaging ability (Figure 8). Both A549 (normal cells) and A549/DDP (cisplatin-resistant cells) cells exhibit the red fluorescence signal that is emitted from Pt NCs-based drugs, while the cell nuclei are stained by $4^{\prime}$,6-diamidino-2-phenylindole (DAPI) exhibiting the blue fluorescence. Most interesting finding is that Pt NCs preferably enter almost cell nuclei in the cisplatinresistant A549/DDP cell groups, compared to the A549 cell group where the Pt NCs are observed evenly distributed in both cell nuclei and cytoplasm. As a result, Pt NC nanomaterial could realize the visual imaging individually as a fluorophore on the account of the fluorescence effect.

The aim of conjugating the biomolecule is to achieve the deliberate target of the specific tissue. Antibody is a suitable and effective choice. An antibody belonging to proteins has a lot of functional groups (e.g., $-\mathrm{NH}_{2}$ and $-\mathrm{COOH}$ ) which could feasibly react with those groups on the surrounding ligands of NCs by chemical reaction, and then, the presynthesized Pt NC-antibody complex is delivered to express on the certain targeted position via antigen-antibody reaction. This approach could complete the targeted imaging of lesion location. For example, after bounding to the antichemokine receptor antibody (anti-CXCR4-Ab) through a conjugated protein A, blue fluorescent mercaptoacetic acid(MAA-) capped Pt NCs were observed on the cell membranes where the receptors are expressed (Figure 9) [130]. In order to check this specific combination of antibodymodified $\mathrm{Pt}_{5}(\mathrm{MAA})_{8}$-protein A-anti-CXCR4-Ab complex and chemokine receptor, Chinese hamster ovary (CHO-K1) cells were selected as a control group due to their negative behaviours against the chemokine receptor. The result indicated that the Pt NC complex cannot stain the CHO-K1 cells, proving the success in the targeted imaging. Simultaneously, the same work was also done for green-emitting Pt NCs [131]. Most importantly, these reported that Pt NCs have the considerably low cytotoxicity and excellent biocompatibility, demonstrating enormous potential in the tracking, imaging, and labelling of cancer cells or other kinds of cells as an alternative fluorescently labelled probe.

Similarly, yellow fluorescent PEI-stabilized Pt NCs (Pt NCs@PEI) could effortlessly conjugate with an antichemokine receptor antibody and then successfully realized the double staining of HeLa cells using DAPI-stained nuclei and Pt NCs@PEI expressed on the cell membrane (Figure 10) [188]. To achieve targeted expression on the cell membrane, a simple glutaraldehyde method was used to conjugate Pt NCs@PEI to the anti-CXCR4-Ab. Confocal fluorescence images show HeLa cell nuclei in blue color (DAPI stained) and cell membranes as yellow color, demonstrating the evidence that the usage of Pt NCs@PEI will not be affected by any other fluorophores, simultaneously. Furthermore, the relationship between NCs and PEI ligands was also checked and the results elucidate that these Pt NCs are stabilized mostly by primary amine. Based on this discovery, the fluorescence of Pt NCs may be originated via two pathways, that is, the electronic transitions between HOMO-LUMO energy levels of Pt NCs and the NCs' surface surrounding ligands through LMCT.

4.2. Antitumour Drugs. Pt-based antitumour drugs are one of the most effective tools for the treatment of different tumours, and Food and Drug Administration (FDA) authorized the $\mathrm{Pt}$ as the effective antitumour drugs for various cancer therapies in 1978 [127, 189-192]. Cisplatin in the Pt(II) state as a representative drug emerged a few deficiencies which influences the therapeutic efficiency. For instance, it could have side effect like myelosuppression, nephrotoxicity, and neurotoxicity in the course of medicine treatment [193195]. On the other hand, typical breast, colorectal, and prostate cancers exhibit less sensitive to cisplatin [196, 197]. More serious is that testicular and ovarian cancers intrinsically resist to cisplatin treatment after several cycles of therapy, even though it is efficient at the beginning stage [198]. These drawbacks including the systemic toxicities and poor specificity impede their anticancer efficiency; therefore, developing a new-type Pt-based antitumour drug with little side effect and excellent specificity could afford a powerful supporting technique for diagnosis and treatment of diverse malignant tumours.

In the current years, Pt NPs and NCs have been used to develop the latest Pt-based anticancer nanomedicine and found their preferable ability of inducing the apoptosis of 
several cancer diseases $[160,199,200]$. Chien et al. reported a low-generation dendrimer-caged $\mathrm{Pt}$ NCs (CPN) with $0.93 \mathrm{~nm}$ diameter [201]. After attaching to the cleavable polyethylene glycol (PEG) corona and targetable iRGD (CRGDKGPDC), this complex achieved the targeting of human breast cancer cell line MDA-MB-231 and release of toxins against malignant cells by affecting tumour-inside activation for anticancer chemotherapeutics (Figure 11). By means of subcutaneous breast cancer xenograft in mice, the therapeutic effect of CPN was examined via intratumoural injection in vivo and the result indicated that this kind of chemotherapeutics has the same efficacy compared to cisplatin.

Fluorescent GSH-capped Pt NCs were prepared by a green and simple chemical method and employed to biolabel the HepG2 cells [202]. It is worth noting that the synthesized Pt NCs could obviously kill the HeLa cells under the irradiation by infrared (IR) light, while it was not happened under UV light condition. The killing mechanism of cancer cells is contributed to heating effect instead of free radical effect. Xia et al. presented an approach to package the Pt NCs with polypeptide and targeting peptide SP9443 to form the assembled Pt NAs. These Pt NAs could damage DNA through targeting disseminated hepatocellular carcinoma (HCC) tumour-initiating cancer stem-like cells (CSLCs) to achieve inhibiting proliferation of tumours [203]. Gene expression profile analysis proved that ABCG2 and CD24, which expressed highly in the sorted SP+CD24+ cells, could be adjusted by Pt NAs, while the cisplatin could not downregulate. Furthermore, real-time quantitative polymerase chain reaction (RT-qPCR) analysis also demonstrated that $\mathrm{Pt}$ NAs induced the downregulation of CCNB1, CDK1, and TOP2A, leading to DNA damage and modulation of the cell cycle (Figure 12). This study verified that the prepared ultrafine Pt NAs have the ability to accelerate the release of toxic $\mathrm{Pt}$ ions and overcome the cisplatin-resistant problem for HCC CLSCs.

In a previous study, we used the dual-functional Pt NCsbased anticancer materials to biologically image the blood system suspension cells as the fluorescent markers. Meanwhile, the selective inhibition of hematopoietic K562 and BV173 cancer cells was investigated as well [186]. The relative cell apoptotic rate for K562 and BV173 cancer cells is three times higher than hematopoietic normal cell (PBMCs) via induction of the expression of p53, PUMA, and cleaved caspase-3 proteins (Figure 13). These Pt NCs manifest the evident apoptosis efficacy possibly due to the inherent characteristic of $\mathrm{Pt}$ and exhibit a great potential in effective treatment of hematopoietic system disease, especially acute myeloid leukaemia and lymphoma. Currently, the cisplatinresistant-non-small-cell lung cancer (NSCLC) was chosen as the targeted object because the lung cancer incidence is increasing continually owing to the environment deterioration and smoking. The problem of drug resistance seriously affects the chemotherapy efficiency and survival rate of patients during the treatment with chemotherapy drugs due to multiple mechanism, such as the lack of effective drug concentration in tumour cells, reduction of drug activity, cell apoptosis changes, and DNA repair pathways. The experimental results illustrated that $\mathrm{Pt}$ NCs-based anticancer drug could achieve the excellent induced apoptosis in both cisplatin-resistant A549/DDP and non-cisplatin-resistant A549 cells [187]. More interesting is that cisplatin-resistant A549/DDP showed the superior inhibitory and apoptotic effects than non-cisplatin-resistant A549 cells by the way of activating p53 protein and the related signalling pathway, which could be proved through the apparent endocytosis behaviour by the nucleus of cisplatin-resistant A549/DDP cells. As for NSCLC, the synthesized Pt NCs-based anticancer drugs could overcome the toxic side effects and drug resistance to enhance the clinical therapeutic effect.

In contrast to the well-known cisplatin resistance mechanism concerning about antiapoptotic factors that counteract caspase activation (Figure 14(a)), the mechanism for Pt NCs-based nanomedicine is still inconclusive. Some researches assume that ultrafine Pt subnanomaterials possess extreme tiny size approximately $1 \mathrm{~nm}$, leading to near $90 \%$ of Pt atoms exposed on the NC's surface. This kind of high surface-active Pt NCs is affected by intracellular acidic organelles like endosomes and lysosomes and then rapidly decomposed to form oxidation states of $\mathrm{Pt}$ (Figure 14(b)) [204]. These corrosive Pt trends to combine with DNA or proteins and then destroy the DNA consequently, resulting in the apoptosis of cancer cells. In addition, ultrafine Pt NCs have an ability to anchor onto the grooves of DNA double helix to further damage the DNA. Thus, the reasonable and receivable mechanism for the Pt NCs-based chemotherapeutics may be summarized as the synergistic effect of both Pt NCs and Pt ions causing the damage of DNA to kill the cancer cells.

4.3. Antibacteria. The usage of noble metal (Ag and $\mathrm{Au})$ as antimicrobial agents was largely investigated, especially for Ag-based nanomaterials [205]. The mechanisms of antibacteria are related to the DNA damage, membrane damage, and production of some active radicals (e.g., reactive oxygen species (ROS)). Because of the ultrafine size of NCs, Ag NCs with higher surface-to-volume ratios and abundant surface atoms express higher antimicrobial efficiency. However, the antibacterial feature of Pt NCs is rarely studied. Subramaniyan et al. put forward the green synthesis protocol employing phytoprotein obtained from spinach leaves as a ligand to gain spherical Pt NCs with the average size of $5 \mathrm{~nm}$ and selfassembled species at the size range from 100 to $250 \mathrm{~nm}$ [206]. These protein-stabilized Pt NCs have the excellent Salmonella typhi-inhibiting ability, and the minimum inhibitory concentration (MIC) was determined at $12.5 \mu \mathrm{M}$ (Figure 15). The inhibition effect was proved as the damage of established biofilms, confirmed by scanning electron microscopy (SEM) and fluorescence microscopy. Moreover, intracellular ROS generated by Pt NCs was also the ancillary killer to Salmonella typhi via oxidative injury against the antioxidant defence.

\section{Conclusions and Outlook}

Conclusively, Pt NCs containing few to dozens of atoms exhibit unique physicochemical properties due to their molecule-like behaviours such as discrete electronic state 
and size-dependent fluorescence. The synthesis of Pt NCs can be divided into two ways: template-assisted approach that is related to designed properties, controllable size, and specific morphology and template-free protocol which has access to the feasible posttreatment process and pure product. Subsequently, the optical, catalytic, and thermal properties of Pt NCs were introduced and these features have a strong relationship with the distinct electronic and structural characteristics, as well as the various surrounding ligands. Breaking the traditional concepts, ultrafine Pt NCs exhibit the favourable catalytic abilities even in the form of less symmetric topological structure. Most importantly, the diverse biological applications of Pt NCs were summarized in detail. Fluorescent Pt NCs have already bioimaged different kinds of tumours like HeLa cells, hematopoietic K569 and BV173 cells, NSCLC A549 cells, and HepG2 cells, as a preferred fluorophore in contrast to traditional fluorescent labels. Moreover, Pt NCs were employed as new class chemotherapeutics in the diagnoses and treatment of hematopoietic, lung, and hepatocellular malignant tumours, exhibiting excellent therapy effect, especially overcoming the problem of cisplatin resistance. Finally, Pt NCs were identified to possess a good antibacterial capacity which could be used as an alternative of the $\mathrm{Ag}$ antibacterial material.

Despite these exciting and promising progress of $\mathrm{Pt}$ NCs mentioned above, the study of ultrafine Pt NCs is at the beginning stage and there still remains a great challenge as follows: (1) synthesis of NIR fluorescent Pt NCs with outstanding optical features, (2) evident clarification of the apoptosis pathway and mechanism of Pt NCs for hematopoietic tumour and cisplatin-resistant NSCLC, (3) valid combination of $\mathrm{Pt} \mathrm{NCs}$ with other materials to endow multifunctionality, and (4) comprehensive utilization of Pt NCs in diverse biological applications, not only for the different tissue systems (like osteocarcinoma and pancreatic carcinoma) but also the application types that need to be extended such as gene therapy, DNA sensing, and protein detection.

\section{Conflicts of Interest}

The authors declare that there is no conflict of interest regarding the publication of this paper.

\section{Acknowledgments}

This research was funded by the National Natural Science Foundation of China (21807121), Key Scientific Research Projects of High Education of Henan Province (18A430005), and Project for Fundamental Research Funds of Zhongyuan University of Technology (K2018YY020). Dr. X.H. gratefully acknowledges the Collaborative Innovation Centre of Textile and Garment Industry, Henan Province, for their assistance and the support from the 2019 Youth Talents Promotion Project of Henan Province, the 2018 Backbone Teachers of Zhongyuan University of Technology, and the Program for Interdisciplinary Direction Team in Zhongyuan University of Technology, China.

\section{References}

[1] W. P. Griffith, The Chemistry of the Rarer Platinum Metals (Os, Ru, Ir, and $R h$ ), Interscience Publishers, 1967.

[2] F. R. Hartley, The Chemistry of Platinum and Palladium: With Particular Reference to Complexes of the Elements, Applied Science Publishers Ltd., 1973.

[3] X. Huang, Polymer Ligand Stabilized Fluorescent Platinum Nanoclusters: Synthesis, Characterization, and Their Applications, Osaka University, 2016.

[4] R. W. Siegel, "Nanostructured materials -mind over matter," Nanostructured Materials, vol. 4, no. 1, pp. 121-138, 1994.

[5] P. C. Ray, "Size and shape dependent second order nonlinear optical properties of nanomaterials and their application in biological and chemical sensing," Chemical Reviews, vol. 110, no. 9, pp. 5332-5365, 2010.

[6] X. Jiang, B. Du, Y. Huang, and J. Zheng, "Ultrasmall noble metal nanoparticles: breakthroughs and biomedical implications," Nano Today, vol. 21, pp. 106-125, 2018.

[7] G. Mie, "Beiträge zur optik trüber medien, speziell kolloidaler metallösungen (Contributions to the optics of diffuse media, especially colloid metal solutions)," Annals of Physics, vol. 330, no. 3, pp. 377-445, 1908.

[8] P. K. Jain, X. Huang, I. H. El-Sayed, and M. A. El-Sayed, "Noble metals on the nanoscale: optical and photothermal properties and some applications in imaging, sensing, biology, and medicine," Accounts of Chemical Research, vol. 41, no. 12, pp. 1578-1586, 2008.

[9] M. Faraday, "XLVII. Experimental relations of gold (and other metals) to light. - The Bakerian lecture," The London, Edinburgh, and Dublin Philosophical Magazine and Journal of Science, vol. 14, no. 95, pp. 401-417, 1857.

[10] H. Kang, J. T. Buchman, R. S. Rodriguez et al., "Stabilization of silver and gold nanoparticles: preservation and improvement of plasmonic functionalities," Chemical Reviews, vol. 119, no. 1, pp. 664-699, 2019.

[11] A. Amirjani and D. F. Haghshenas, "Ag nanostructures as the surface plasmon resonance (SPR)?based sensors: a mechanistic study with an emphasis on heavy metallic ions detection," Sensors and Actuators B: Chemical, vol. 273, pp. 1768-1779, 2018.

[12] M. M. Alvarez, J. T. Khoury, T. G. Schaaff, M. N. Shafigullin, I. Vezmar, and R. L. Whetten, "Optical absorption spectra of nanocrystal gold molecules," The Journal of Physical Chemistry B, vol. 101, no. 19, pp. 3706-3712, 1997.

[13] S. K. Ghosh and T. Pal, "Interparticle coupling effect on the surface plasmon resonance of gold nanoparticles: from theory to applications," Chemical Reviews, vol. 107, no. 11, pp. 4797-4862, 2007.

[14] E. Konował, A. Modrzejewska-Sikorska, M. Motylenko et al., "Functionalization of organically modified silica with gold nanoparticles in the presence of lignosulfonate," International Journal of Biological Macromolecules, vol. 85, pp. 7481, 2016.

[15] A. Modrzejewska-Sikorska, E. Konował, A. Cichy, M. Nowicki, T. Jesionowski, and G. Milczarek, "The effect of silver salts and lignosulfonates in the synthesis of lignosulfonate-stabilized silver nanoparticles," Journal of Molecular Liquids, vol. 240, pp. 80-86, 2017.

[16] Q. Tong, W. Wang, Y. Fan, and L. Dong, "Recent progressive preparations and applications of silver-based SERS substrates," 
TrAC Trends in Analytical Chemistry, vol. 106, pp. 246-258, 2018.

[17] G. Schmid, "Large clusters and colloids. Metals in the embryonic state," Chemical Reviews, vol. 92, no. 8, pp. 1709-1727, 1992.

[18] F. A. Cotton and T. E. Haas, "A molecular orbital treatment of the bonding in certain metal atom clusters," Inorganic Chemistry, vol. 3, no. 1, pp. 10-17, 1964.

[19] L. Yu, L. Zhang, G. Ren et al., "Multicolorful fluorescentnanoprobe composed of $\mathrm{Au}$ nanocluster and carbon dots for colorimetric and fluorescent sensing $\mathrm{Hg}^{2+}$ and $\mathrm{Cr}^{6+}$," Sensors and Actuators B: Chemical, vol. 262, pp. 678-686, 2018.

[20] M. I. Halawa, J. Lai, and G. Xu, "Gold nanoclusters: synthetic strategies and recent advances in fluorescent sensing," Materials Today Nano, vol. 3, pp. 9-27, 2018.

[21] H. Yu, B. Rao, W. Jiang, S. Yang, and M. Zhu, "The photoluminescent metal nanoclusters with atomic precision," Coordination Chemistry Reviews, vol. 378, pp. 595-617, 2019.

[22] R. Jin, "Atomically precise metal nanoclusters: stable sizes and optical properties," Nanoscale, vol. 7, no. 5, pp. 1549$1565,2015$.

[23] R. Jin, C. Zeng, M. Zhou, and Y. Chen, "Atomically precise colloidal metal nanoclusters and nanoparticles: fundamentals and opportunities," Chemical Reviews, vol. 116, no. 18, pp. 10346-10413, 2016.

[24] T.-H. Lee, J. I. Gonzalez, J. Zheng, and R. M. Dickson, "Single-molecule optoelectronics," Accounts of Chemical Research, vol. 38, no. 7, pp. 534-541, 2005.

[25] S. Morawiec, M. J. Mendes, F. Priolo, and I. Crupi, "Plasmonic nanostructures for light trapping in thin-film solar cells," Materials Science in Semiconductor Processing, vol. 92, pp. 10-18, 2019.

[26] F. Lu, H. Yang, Z. Yuan, T. Nakanishi, C. Lu, and Y. He, "Highly fluorescent polyethyleneimine protected $\mathrm{Au}_{8}$ nanoclusters: one-pot synthesis and application in hemoglobin detection," Sensors and Actuators B: Chemical, vol. 291, pp. 170-176, 2019.

[27] N. Xiao, J. X. Dong, S. G. Liu et al., "Multifunctional fluorescent sensors for independent detection of multiple metal ions based on Ag nanoclusters," Sensors and Actuators B: Chemical, vol. 264, pp. 184-192, 2018.

[28] S. Ghosh, J. R. Bhamore, N. I. Malek, Z. V. P. Murthy, and S. K. Kailasa, "Trypsin mediated one-pot reaction for the synthesis of red fluorescent gold nanoclusters: sensing of multiple analytes (carbidopa, dopamine, $\mathrm{Cu}^{2+}, \mathrm{Co}^{2+}$ and $\mathrm{Hg}^{2+}$ ions)," Spectrochimica Acta Part A: Molecular and Biomolecular Spectroscopy, vol. 215, pp. 209-217, 2019.

[29] X. Y. Wang, G. B. Zhu, W. D. Cao et al., "A novel ratiometric fluorescent probe for the detection of uric acid in human blood based on $\mathrm{H}_{2} \mathrm{O}_{2}$-mediated fluorescence quenching of gold/silver nanoclusters," Talanta, vol. 191, pp. 46-53, 2019.

[30] J. D. Aiken III and R. G. Finke, "A review of modern transition-metal nanoclusters: their synthesis, characterization, and applications in catalysis," Journal of Molecular Catalysis A: Chemical, vol. 145, no. 1-2, pp. 1-44, 1999.

[31] Y. Zhang, C. Zhang, C. Xu et al., "Ultrasmall Au nanoclusters for biomedical and biosensing applications: a mini-review," Talanta, vol. 200, pp. 432-442, 2019.

[32] L. N. Lewis, "Chemical catalysis by colloids and clusters," Chemical Reviews, vol. 93, no. 8, pp. 2693-2730, 1993.
[33] J. Wu and $\mathrm{H}$. Yang, "Platinum-based oxygen reduction electrocatalysts," Accounts of Chemical Research, vol. 46, no. 8, pp. 1848-1857, 2013.

[34] Z. Peng and H. Yang, "Designer platinum nanoparticles: control of shape, composition in alloy, nanostructure and electrocatalytic property," Nano Today, vol. 4, no. 2, pp. 143-164, 2009.

[35] H. Xiao, L. Yan, E. M. Dempsey et al., "Recent progress in polymer-based platinum drug delivery systems," Progress in Polymer Science, vol. 87, pp. 70-106, 2018.

[36] A. V. Klein and T. W. Hambley, "Platinum drug distribution in cancer cells and tumors," Chemical Reviews, vol. 109, no. 10, pp. 4911-4920, 2009.

[37] A. Chen and P. Holt-Hindle, "Platinum-based nanostructured materials: synthesis, properties, and applications," Chemical Reviews, vol. 110, no. 6, pp. 3767-3804, 2010.

[38] R. Jin, "Quantum sized, thiolate-protected gold nanoclusters," Nanoscale, vol. 2, no. 3, pp. 343-362, 2010.

[39] Y. Wang, H. Guo, Y. Zhang et al., "Achieving highly watersoluble and luminescent gold nanoclusters modified by $\beta$ cyclodextrin as multifunctional nanoprobe for biological applications," Dyes and Pigments, vol. 157, pp. 359-368, 2018.

[40] I. Diez and R. H. A. Ras, "Fluorescent silver nanoclusters," Nanoscale, vol. 3, no. 5, pp. 1963-1970, 2011.

[41] C.-H. Lu and F.-C. Chang, "Polyhedral oligomeric silsesquioxane-encapsulating amorphous palladium nanoclusters as catalysts for heck reactions," ACS Catalysis, vol. 1, no. 5, pp. 481-488, 2011.

[42] X. Liu and D. Astruc, "Atomically precise copper nanoclusters and their applications," Coordination Chemistry Reviews, vol. 359, pp. 112-126, 2018

[43] Q. Yao, T. Chen, X. Yuan, and J. Xie, "Toward total synthesis of thiolate-protected metal nanoclusters," Accounts of Chemical Research, vol. 51, no. 6, pp. 1338-1348, 2018.

[44] B. Helmut and S. Nagabhushana Kyatanahalli, "Chapter 2 metal nanoclusters: synthesis and strategies for their size control," in Metal nanoclusters in catalysis and materials science: the issue of size control, pp. 21-48, Elsevier, 2008.

[45] O. Kylián, J. Prokeš, O. Polonskyi et al., "Deposition and characterization of $\mathrm{Pt}$ nanocluster films by means of gas aggregation cluster source," Thin Solid Films, vol. 571, pp. 13-17, 2014.

[46] K. Sokołowska, S. Malola, M. Lahtinen et al., "Towards controlled synthesis of water-soluble gold nanoclusters: synthesis and analysis," Journal of Physical Chemistry C, vol. 123, no. 4, pp. 2602-2612, 2019.

[47] S. W. Cho, H. J. Kim, Y. N. Cho, J. H. Jeong, and H. Kong, "Top-down synthesis of polyaspartamide morphogens to derive platinum nanoclusters," Materials Letters, vol. 168, pp. 184-187, 2016.

[48] R. R. Nasaruddin, T. Chen, N. Yan, and J. Xie, "Roles of thiolate ligands in the synthesis, properties and catalytic application of gold nanoclusters," Coordination Chemistry Reviews, vol. 368, pp. 60-79, 2018.

[49] W. W. Weare, S. M. Reed, M. G. Warner, and J. E. Hutchison, "Improved synthesis of small $\left(d_{\mathrm{CORE}} \approx 1.5 \mathrm{~nm}\right)$ phosphinestabilized gold nanoparticles," Journal of the American Chemical Society, vol. 122, no. 51, pp. 12890-12891, 2000.

[50] Ö. Metin, S. Duman, M. Dinç, and S. Özkar, "Oleylaminestabilized palladium(0) nanoclusters as highly active 
heterogeneous catalyst for the dehydrogenation of ammonia borane," The Journal of Physical Chemistry C, vol. 115, no. 21, pp. 10736-10743, 2011.

[51] J. Xu, X. Wu, G. Fu et al., "Fabrication of phosphonate functionalized platinum nanoclusters and their application in hydrogen peroxide sensing in the presence of oxygen," Electrochimica Acta, vol. 80, pp. 233-239, 2012.

[52] J. Ma, S. Reng, D. Pan, R. Li, and K. Xie, "PVP-Pt nanoclusters supported zeolite catalysts for converting methane to higher hydrocarbon at low temperature," Reactive and Functional Polymers, vol. 62, no. 1, pp. 31-39, 2005.

[53] I. Díez, M. Pusa, S. Kulmala et al., "Color tunability and electrochemiluminescence of silver nanoclusters," Angewandte Chemie International Edition, vol. 48, no. 12, pp. 2122-2125, 2009.

[54] R. M. Crooks, B. I. Lemon, L. Sun, L. K. Yeung, and M. Zhao, "Dendrimer-encapsulated metals and semiconductors: synthesis, characterization, and applications," in Dendrimers III, F. Vögtle, Ed., vol. 212 of Topics in Current Chemistry, pp. 81-135, Springer, Berlin, Heidelberg, 2001.

[55] X. Huang, H. Zhang, L. Liang, and B. Tan, "Preparation of nanoparticles with multi-functional water-soluble polymer ligands," Progress in Chemistry, vol. 22, no. 5, pp. 953-961, 2010.

[56] N. Erathodiyil and J. Y. Ying, "Functionalization of inorganic nanoparticles for bioimaging applications," Accounts of Chemical Research, vol. 44, no. 10, pp. 925-935, 2011.

[57] A. Lopez and J. Liu, "DNA-templated fluorescent gold nanoclusters reduced by good's buffer: from blue-emitting seeds to red and near infrared emitters," Canadian Journal of Chemistry, vol. 93, no. 6, pp. 615-620, 2015.

[58] W. Y. Mu, R. Yang, A. Robertson, and Q. Y. Chen, "A nearinfrared BSA coated DNA-AgNCs for cellular imaging," Colloids and Surfaces B: Biointerfaces, vol. 162, pp. 427-431, 2018.

[59] A. Aires, I. Llarena, M. Moller, J. Castro-Smirnov, J. Cabanillas-Gonzalez, and A. L. Cortajarena, "A simple approach to design proteins for the sustainable synthesis of metal nanoclusters," Angewandte Chemie International Edition, vol. 58, no. 19, pp. 6214-6219, 2019.

[60] S. M. Ghoreishian, S. M. Kang, G. Seeta Rama Raju et al., " $\gamma$-Radiolysis as a highly efficient green approach to the synthesis of metal nanoclusters: a review of mechanisms and applications," Chemical Engineering Journal, vol. 360, pp. 1390-1406, 2019.

[61] B. A. Roberts and C. R. Strauss, "Toward rapid, "green", predictable microwave-assisted synthesis," Accounts of Chemical Research, vol. 38, no. 8, pp. 653-661, 2005.

[62] H. Xu, B. W. Zeiger, and K. S. Suslick, "Sonochemical synthesis of nanomaterials," Chemical Society Reviews, vol. 42, no. 7, pp. 2555-2567, 2013.

[63] K. Watanabe, D. Menzel, N. Nilius, and H.-J. Freund, "Photochemistry on metal nanoparticles," Chemical Reviews, vol. 106, no. 10, pp. 4301-4320, 2006.

[64] R. A. Hackendorn and A. V. Virkar, "Synthesis of platinum nanoclusters and electrochemical investigation of their stability," Journal of Power Sources, vol. 240, pp. 618-629, 2013.

[65] X. Yuan, Z. Luo, Q. Zhang et al., "Synthesis of highly fluorescent metal $(\mathrm{Ag}, \mathrm{Au}, \mathrm{Pt}$, and $\mathrm{Cu})$ nanoclusters by electrostati- cally induced reversible phase transfer," ACS Nano, vol. 5, no. 11, pp. 8800-8808, 2011.

[66] I. Chakraborty, R. G. Bhuin, S. Bhat, and T. Pradeep, "Blue emitting undecaplatinum clusters," Nanoscale, vol. 6, no. 15, pp. 8561-8564, 2014.

[67] L. Wang, S. Ouyang, B. Liu, R. Yang, T. Wang, and S. Wang, "One-pot synthesis of octahedral platinum nanoclusters with enhanced electrocatalytic activities," Materials Research Bulletin, vol. 61, pp. 357-362, 2015.

[68] R. W. J. Scott, O. M. Wilson, and R. M. Crooks, "Synthesis, characterization, and applications of dendrimerencapsulated nanoparticles," The Journal of Physical Chemistry B, vol. 109, no. 2, pp. 692-704, 2005.

[69] Y. Borodko, C. M. Thompson, W. Huang, H. B. Yildiz, H. Frei, and G. A. Somorjai, "Spectroscopic study of platinum and rhodium dendrimer (PAMAM G4OH) compounds: structure and stability," The Journal of Physical Chemistry C, vol. 115, no. 11, pp. 4757-4767, 2011.

[70] P. Maity, S. Yamazoe, and T. Tsukuda, "Dendrimer-encapsulated copper cluster as a chemoselective and regenerable hydrogenation catalyst," ACS Catalysis, vol. 3, no. 2, pp. 182-185, 2013.

[71] H. Lim, Y. Ju, and J. Kim, "Tailoring catalytic activity of Pt nanoparticles encapsulated inside dendrimers by tuning nanoparticle sizes with subnanometer accuracy for sensitive chemiluminescence-based analyses," Analytical Chemistry, vol. 88, no. 9, pp. 4751-4758, 2016.

[72] Y. Borodko, P. Ercius, V. Pushkarev, C. Thompson, and G. Somorjai, "From single Pt atoms to Pt nanocrystals: photoreduction of $\mathrm{Pt}^{2+}$ inside of a PAMAM dendrimer," The Journal of Physical Chemistry Letters, vol. 3, no. 2, pp. 236-241, 2012.

[73] W. Tu and H. Liu, "Continuous synthesis of colloidal metal nanoclusters by microwave irradiation," Chemistry of Materials, vol. 12, no. 2, pp. 564-567, 2000.

[74] H. Zhang, X. Huang, L. Li et al., "Photoreductive synthesis of water-soluble fluorescent metal nanoclusters," Chemical Communications, vol. 48, no. 4, pp. 567-569, 2012.

[75] J. Quinson, L. Kacenauskaite, T. L. Christiansen, T. Vosch, M. Arenz, and K. M. Ø. Jensen, "Spatially localized synthesis and structural characterization of platinum nanocrystals obtained using UV light," ACS Omega, vol. 3, no. 8, pp. 10351-10356, 2018.

[76] P. Wang, F. Li, X. Huang, Y. Li, and L. Wang, "In situ electrodeposition of $\mathrm{Pt}$ nanoclusters on glassy carbon surface modified by monolayer choline film and their electrochemical applications," Electrochemistry Communications, vol. 10, no. 2, pp. 195-199, 2008.

[77] F. Liu, Y. Deng, X. Han, W. Hu, and C. Zhong, "Electrodeposition of metals and alloys from ionic liquids," Journal of Alloys and Compounds, vol. 654, pp. 163-170, 2016.

[78] L. Qian, Y. Liu, Y. Song, Z. Li, and X. Yang, "Electrodeposition of Pt nanoclusters on the surface modified by monolayer poly(amidoamine) dendrimer film," Electrochemistry Communications, vol. 7, no. 12, pp. 1209-1212, 2005.

[79] J. Camacho-Bunquin, M. S. Ferrandon, H. Sohn et al., "Atomically precise strategy to a PtZn alloy nanocluster catalyst for the deep dehydrogenation of $n$-butane to 1,3-butadiene," ACS Catalysis, vol. 8, no. 11, pp. 10058-10063, 2018.

[80] H. Shi, P. S. Thapa, B. Subramaniam, and R. V. Chaudhari, "Oxidation of glucose using mono- and bimetallic catalysts 
under base-free conditions," Organic Process Research \& Development, vol. 22, no. 12, pp. 1653-1662, 2018.

[81] J. Zhang, W. L. Yu, S. H. Zhou, Y. Li, Y.-F. Zhang, and W.-K. Chen, "Nanoclusters $\mathrm{Au}_{19} \mathrm{Pd}$ and $\mathrm{Au}_{19} \mathrm{Pt}$ catalyzing CO oxidation: a density functional study," Chinese Journal of Structural Chemistry, vol. 37, no. 12, pp. 1849-1859, 2018.

[82] K. Li, Y. Li, Y. Wang, J. Ge, C. Liu, and W. Xing, "Enhanced electrocatalytic performance for the hydrogen evolution reaction through surface enrichment of platinum nanoclusters alloying with ruthenium in situ embedded in carbon," Energy \& Environmental Science, vol. 11, no. 5, pp. 1232-1239, 2018.

[83] X. L. Chen, L. Zhang, J. J. Feng et al., "Facile solvothermal fabrication of polypyrrole sheets supported dendritic platinum-cobalt nanoclusters for highly efficient oxygen reduction and ethylene glycol oxidation," Journal of Colloid and Interface Science, vol. 530, pp. 394-402, 2018.

[84] V. Sharma, S. Kumar, and V. Krishnan, "Homogeneously embedded Pt nanoclusters on amorphous titania matrix as highly efficient visible light active photocatalyst material," Materials Chemistry and Physics, vol. 179, pp. 129-136, 2016.

[85] A. S. Maldonado, C. I. N. Morgade, S. B. Ramos, and G. F. Cabeza, "Comparative study of $\mathrm{CO}$ adsorption on planar and tetrahedral Pt nanoclusters supported on $\mathrm{TiO}_{2}(110)$ stoichiometric and reduced surfaces," Molecular Catalysis, vol. 433, pp. 403-413, 2017.

[86] M. Torabi, R. Karimi Shervedani, and A. Amini, "High performance porous graphene nanoribbons electrodes synthesized via hydrogen plasma and modified by Pt-Ru nanoclusters for charge storage and methanol oxidation," Electrochimica Acta, vol. 290, pp. 616-625, 2018.

[87] L. Sun, B. Wang, and Y. Wang, "A Schottky-junction-based platinum nanoclusters@silicon carbide nanosheet as longterm stable hydrogen sensors," Applied Surface Science, vol. 473, pp. 641-648, 2019.

[88] L. Lu, "Highly sensitive detection of nitrite at a novel electrochemical sensor based on mutually stabilized Pt nanoclusters doped CoO nanohybrid," Sensors and Actuators B: Chemical, vol. 281, pp. 182-190, 2019.

[89] X. Zuo, H. Liu, D. Guo, and X. Yang, "Enantioselective hydrogenation of pyruvates over polymer-stabilized and supported platinum nanoclusters," Tetrahedron, vol. 55, no. 25 , pp. $7787-7804,1999$.

[90] K. A. Carrado, G. Sandi, R. Kizilel, S. Seifert, and N. Castagnola, "Platinum nanoclusters immobilized on polymer-clay nanocomposite films," Applied Clay Science, vol. 30, no. 2, pp. 94-102, 2005.

[91] Z. Marco, C. Paolo, and C. Benedetto, "Chapter 10 - metal nanoclusters supported on cross-linked functional polymers: a class of emerging metal catalysts," in Metal Nanoclusters in Catalysis and Materials Science: the issue of size control, pp. 201-232, Elsevier, 2008.

[92] L. Jia, D. A. Bulushev, O. Y. Podyacheva et al., "Pt nanoclusters stabilized by $\mathrm{N}$-doped carbon nanofibers for hydrogen production from formic acid," Journal of Catalysis, vol. 307, pp. 94-102, 2013.

[93] M. F. Luo, W. H. Wen, C. S. Lin, C. I. Chiang, S. D. Sartale, and M. S. Zei, "Structures of Co and Pt nanoclusters on a thin film of $\mathrm{Al}_{2} \mathrm{O}_{3} / \mathrm{NiAl}(100)$ from reflection high-energy electron diffraction and scanning-tunnelling microscopy," Surface Science, vol. 601, no. 10, pp. 2139-2146, 2007.
[94] M. F. Luo, W. R. Lin, W. H. Wen, and B. W. Chang, "Methanol electro-oxidation and induced sintering on Pt nanoclusters supported on thin-film $\mathrm{Al}_{2} \mathrm{O}_{3} / \mathrm{NiAl}(100)$," Surface Science, vol. 602, no. 21, pp. 3258-3265, 2008.

[95] C. S. Chao, T. W. Liao, C. X. Wang, Y. D. Li, T. C. Hung, and M. F. Luo, "Obstruction by CO of the decomposition of methanol on Pt nanoclusters on a thin film of $\mathrm{Al}_{2} \mathrm{O}_{3} / \mathrm{NiAl}(100)$," Applied Surface Science, vol. 293, pp. 352-358, 2014.

[96] A. S. Bazhenov and K. Honkala, "Globally optimized equilibrium shapes of zirconia-supported $\mathrm{Rh}$ and Pt nanoclusters: insights into site assembly and reactivity," The Journal of Physical Chemistry C, vol. 123, no. 12, pp. 7209-7216, 2019.

[97] M. Mon, M. A. Rivero-Crespo, J. Ferrando-Soria et al., "Synthesis of densely packaged, ultrasmall $\mathrm{Pt}^{0}{ }_{2}$ clusters within a thioether-functionalized MOF: catalytic activity in industrial reactions at low temperature," Angewandte Chemie International Edition, vol. 57, no. 21, pp. 6186-6191, 2018.

[98] C. Feng and P. He, "Atomistic investigation on the diffusion mechanism of Pt nanoclusters on well-aligned multi-walled carbon nanotubes," Computational Materials Science, vol. 103, pp. 157-164, 2015.

[99] H. Huang, Z. He, X. Lin, W. Ruan, Y. Liu, and Z. Yang, "Ultradispersed platinum nanoclusters on polydopaminefunctionalized carbon nanotubes as an excellent catalyst for methanol oxidation reaction," Applied Catalysis A: General, vol. 490, pp. 65-70, 2015.

[100] I. Fampiou and A. Ramasubramaniam, "Influence of support effects on CO oxidation kinetics on CO-saturated graphenesupported $\mathrm{Pt}_{13}$ nanoclusters," The Journal of Physical Chemistry C, vol. 119, no. 16, pp. 8703-8710, 2015.

[101] P. Y. Cai, Y. W. Huang, Y. C. Huang et al., "Atomic structures of Pt nanoclusters supported on graphene grown on $\mathrm{Pt}(111)$," The Journal of Physical Chemistry C, vol. 122, no. 28, pp. 16132-16141, 2018.

[102] F. Düll, F. Späth, U. Bauer et al., "Reactivity of CO on sulfurpassivated graphene-supported platinum nanocluster arrays," The Journal of Physical Chemistry C, vol. 122, no. 28, pp. 16008-16015, 2018.

[103] X. Liu, Y. Tang, M. Shen et al., "Bifunctional CO oxidation over Mn-mullite anchored Pt sub-nanoclusters via atomic layer deposition," Chemical Science, vol. 9, no. 9, pp. 24692473, 2018.

[104] D. Lee, Y. Kim, Y. Kwon et al., "Boosting the electrocatalytic glycerol oxidation performance with highly-dispersed $\mathrm{Pt}$ nanoclusters loaded on 3D graphene-like microporous carbon," Applied Catalysis B: Environmental, vol. 245, pp. 555-568, 2019.

[105] Z. Wang, G. Zhang, Z. Zhong, Y. Lin, and Z. Su, "In-situ synthesis of platinum nanoclusters in polyelectrolyte multilayer films," Thin Solid Films, vol. 660, pp. 59-64, 2018.

[106] M. Hyotanishi, Y. Isomura, H. Yamamoto, H. Kawasaki, and Y. Obora, "Surfactant-free synthesis of palladium nanoclusters for their use in catalytic cross-coupling reactions," Chemical Communications, vol. 47, no. 20, pp. 5750-5752, 2011.

[107] H. Kawasaki, H. Yamamoto, H. Fujimori, R. Arakawa, M. Inada, and Y. Iwasaki, "Surfactant-free solution synthesis of fluorescent platinum subnanoclusters," Chemical Communications, vol. 46, no. 21, pp. 3759-3761, 2010.

[108] P. N. Duchesne and P. Zhang, "Local structure of fluorescent platinum nanoclusters," Nanoscale, vol. 4, no. 14, pp. 41994205, 2012. 
[109] A. George, H. Gopalakrishnan, and S. Mandal, "Surfactant free platinum nanocluster as fluorescent probe for the selective detection of Fe (III) ions in aqueous medium," Sensors and Actuators B: Chemical, vol. 243, pp. 332-337, 2017.

[110] P. Yu, X. Wen, Y.-R. Toh, X. Ma, and J. Tang, "Fluorescent metallic nanoclusters: electron dynamics, structure, and applications," Particle \& Particle Systems Characterization, vol. 32, no. 2, pp. 142-163, 2015.

[111] H. Jiang and X.-M. Wang, "Progress of metal nanoclusters-based electrochemiluminescent analysis," Chinese Journal of Analytical Chemistry, vol. 45, no. 12, pp. 1776-1785, 2017.

[112] D. Li, Z. Chen, and X. Mei, "Fluorescence enhancement for noble metal nanoclusters," Advances in Colloid and Interface Science, vol. 250, pp. 25-39, 2017.

[113] S. H. Kim, K. C. Kim, Y. S. Kim, and H. J. Kim, "Abnormal optical changes with the formation of Pt nanoclusters," Current Applied Physics, vol. 6, no. 6, pp. 1036-1039, 2006.

[114] J. Zheng, P. R. Nicovich, and R. M. Dickson, "Highly fluorescent noble-metal quantum dots," Annual Review of Physical Chemistry, vol. 58, no. 1, pp. 409-431, 2007.

[115] A. Heuer-Jungemann, N. Feliu, I. Bakaimi et al., "The role of ligands in the chemical synthesis and applications of inorganic nanoparticles," Chemical Reviews, vol. 119, no. 8, pp. 4819-4880, 2019.

[116] Z. Wu and R. Jin, "On the ligand's role in the fluorescence of gold nanoclusters," Nano Letters, vol. 10, no. 7, pp. 2568-2573, 2010.

[117] J. M. Forward, D. Bohmann, J. P. Fackler, and R. J. Staples, "Luminescence studies of gold(I) thiolate complexes," Inorganic Chemistry, vol. 34, no. 25, pp. 6330-6336, 1995.

[118] M. S. Devadas, J. Kim, E. Sinn, D. Lee, T. Goodson III, and G. Ramakrishna, "Unique ultrafast visible luminescence in monolayer-protected $\mathrm{Au}_{25}$ clusters," Journal of Physical Chemistry C, vol. 114, no. 51, pp. 22417-22423, 2010.

[119] X. Huang, B. Li, L. Li et al., "Facile preparation of highly blue fluorescent metal nanoclusters in organic media," The Journal of Physical Chemistry C, vol. 116, no. 1, pp. 448-455, 2012.

[120] X. Yuan, M. I. Setyawati, A. S. Tan, C. N. Ong, D. T. Leong, and J. Xie, "Highly luminescent silver nanoclusters with tunable emissions: cyclic reduction-decomposition synthesis and antimicrobial properties," NPG Asia Materials, vol. 5, no. 2, article e39, 2013.

[121] E. Gwinn, D. Schultz, S. Copp, and S. Swasey, "DNA-protected silver clusters for nanophotonics," Nanomaterials, vol. 5, no. 1, pp. 180-207, 2015.

[122] Y. S. Ang, W. W. E. Woon, and L. Y. L. Yung, "The role of spacer sequence in modulating turn-on fluorescence of DNA-templated silver nanoclusters," Nucleic Acids Research, vol. 46, no. 14, pp. 6974-6982, 2018.

[123] M. Liu, F. Tang, Z. Yang, J. Xu, and X. Yang, "Recent progress on gold-nanocluster-based fluorescent probe for environmental analysis and biological sensing," Journal of Analytical Methods in Chemistry, vol. 2019, Article ID 1095148, 10 pages, 2019.

[124] S. Shadpour, J. P. Vanegas, A. Nemati, and T. Hegmann, "Amplification of chirality by adenosine monophosphatecapped luminescent gold nanoclusters in nematic lyotropic chromonic liquid crystal tactoids," ACS Omega, vol. 4, no. 1, pp. 1662-1668, 2019.
[125] L. Yang, X. Lou, F. Yu, and H. Liu, "Cross-linking structureinduced strong blue emissive gold nanoclusters for intracellular sensing," Analyst, vol. 144, no. 8, pp. 2765-2772, 2019.

[126] J. V. Frangioni, "In vivo near-infrared fluorescence imaging," Current Opinion in Chemical Biology, vol. 7, no. 5, pp. 626634, 2003.

[127] B. Rosenberg, L. Vancamp, J. E. Trosko, and V. H. Mansour, "Platinum compounds: a new class of potent antitumour agents," Nature, vol. 222, no. 5191, pp. 385-386, 1969.

[128] X. Xia, Y. Zhang, and J. Wang, "Novel fabrication of highly fluorescent Pt nanoclusters and their applications in hypochlorite assay," RSC Advances, vol. 4, no. 48, pp. 2536525368, 2014.

[129] X. Le Guével, V. Trouillet, C. Spies, G. Jung, and M. Schneider, "Synthesis of yellow-emitting platinum nanoclusters by ligand etching," The Journal of Physical Chemistry C, vol. 116, no. 10, pp. 6047-6051, 2012.

[130] S.-I. Tanaka, J. Miyazaki, D. K. Tiwari, T. Jin, and Y. Inouye, "Fluorescent platinum nanoclusters: synthesis, purification, characterization, and application to bioimaging," Angewandte Chemie International Edition, vol. 50, no. 2, pp. 431-435, 2011.

[131] S.-I. Tanaka, K. Aoki, A. Muratsugu, H. Ishitobi, T. Jin, and Y. Inouye, "Synthesis of green-emitting $\mathrm{Pt}_{8}$ nanoclusters for biomedical imaging by pre-equilibrated Pt/PAMAM (G4$\mathrm{OH}$ ) and mild reduction," Optical Materials Express, vol. 3, no. 2, pp. 157-165, 2013.

[132] X. Huang, K. Aoki, H. Ishitobi, and Y. Inouye, "Preparation of Pt nanoclusters with different emission wavelengths and their application in $\mathrm{Co}^{2+}$ detection," ChemPhysChem, vol. 15, no. 4, pp. 642-646, 2014.

[133] N. Xu, H.-W. Li, and Y. Wu, "Hydrothermal synthesis of polyethylenimine-protected high luminescent Ptnanoclusters and their application to the detection of nitroimidazoles," Analytica Chimica Acta, vol. 958, pp. 51-58, 2017.

[134] J. García Fernández, L. Trapiella-Alfonso, J. M. Costa-Fernández, R. Pereiro, and A. Sanz-Medel, "Aqueous synthesis of near-infrared highly fluorescent platinum nanoclusters," Nanotechnology, vol. 26, no. 21, article 215601, 2015.

[135] F. Molaabasi, M. Sarparast, M. Shamsipur et al., "Shape-controlled synthesis of luminescent hemoglobin capped hollow porous platinum nanoclusters and their application to catalytic oxygen reduction and cancer imaging," Scientific Reports, vol. 8, no. 1, article 14507, 2018.

[136] F. Klasovsky and P. Claus, "Chapter 8 - metal nanoclusters in catalysis: effects of nanoparticle size, shape, and structure," in Metal Nanoclusters in Catalysis and Materials Science: the issue of size control, pp. 167-181, Elsevier, 2008.

[137] J. Ustarroz, I. M. Ornelas, G. Zhang et al., "Mobility and poisoning of mass-selected platinum nanoclusters during the oxygen reduction reaction," ACS Catalysis, vol. 8, no. 8, pp. 6775-6790, 2018.

[138] J. Huang and M. Eikerling, "Modeling the oxygen reduction reaction at platinum-based catalysts: a brief review of recent developments," Current Opinion in Electrochemistry, vol. 13, pp. 157-165, 2019.

[139] F. T. Wagner, B. Lakshmanan, and M. F. Mathias, "Electrochemistry and the future of the automobile," The Journal of Physical Chemistry Letters, vol. 1, no. 14, pp. 2204-2219, 2010. 
[140] X. Zhou, Y. Gan, J. du et al., “A review of hollow Pt-based nanocatalysts applied in proton exchange membrane fuel cells," Journal of Power Sources, vol. 232, pp. 310-322, 2013.

[141] F. Zhang, F. Jiao, X. Pan et al., "Tailoring the oxidation activity of Pt nanoclusters via encapsulation," ACS Catalysis, vol. 5, no. 2, pp. 1381-1385, 2015.

[142] G. Ercolano, S. Cavaliere, J. Rozière, and D. J. Jones, "Recent developments in electrocatalyst design thrifting noble metals in fuel cells," Current Opinion in Electrochemistry, vol. 9, pp. 271-277, 2018.

[143] J. Zhang, X. Yan, and H. Liu, "The effects of tin on the hydrogenation of $\alpha$-diketones over platinum nanoclusters," Journal of Molecular Catalysis A: Chemical, vol. 176, no. 1-2, pp. 281286, 2001.

[144] A. S. Crampton, "Hydrogenation reactions on small platinum clusters," in Encyclopedia of Interfacial Chemistry, pp. 465476, Elsevier, 2018.

[145] C. Adlhart and E. Uggerud, "Reactions of platinum clusters $\mathrm{Pt}_{n}{ }^{ \pm}, n=1-21$, with $\mathrm{CH}_{4}$ : to react or not to react," Chemical Communications, no. 24, pp. 2581-2582, 2006.

[146] K. Kon, S. M. A. Hakim Siddiki, and K.-I. Shimizu, "Size- and support-dependent Pt nanocluster catalysis for oxidant-free dehydrogenation of alcohols," Journal of Catalysis, vol. 304, pp. 63-71, 2013.

[147] R. M. Rioux, H. Song, P. Yang, and G. A. Somorjai, "Chapter 7 - platinum nanoclusters' size and surface structure sensitivity of catalytic reactions," in Metal nanoclusters in catalysis and materials science: the issue of size control, pp. 149-166, Elsevier, 2008.

[148] M. Shao, A. Peles, and K. Shoemaker, "Electrocatalysis on platinum nanoparticles: particle size effect on oxygen reduction reaction activity," Nano Letters, vol. 11, no. 9, pp. 3714-3719, 2011.

[149] H. Yano, J. Inukai, H. Uchida et al., "Particle-size effect of nanoscale platinum catalysts in oxygen reduction reaction: an electrochemical and ${ }^{195} \mathrm{Pt}$ EC-NMR study," Physical Chemistry Chemical Physics, vol. 8, no. 42, pp. 4932-4939, 2006.

[150] T. Imaoka, H. Kitazawa, W.-J. Chun, and K. Yamamoto, "Finding the most catalytically active platinum clusters with low atomicity," Angewandte Chemie International Edition, vol. 54, no. 34, pp. 9810-9815, 2015.

[151] S. Vajda, M. J. Pellin, J. P. Greeley et al., "Subnanometre platinum clusters as highly active and selective catalysts for the oxidative dehydrogenation of propane," Nature Materials, vol. 8, no. 3, pp. 213-216, 2009.

[152] Y. Shiraishi, M. Nakayama, E. Takagi, T. Tominaga, and N. Toshima, "Effect of quantity of polymer on catalysis and superstructure size of polymer-protected Pt nanoclusters," Inorganica Chimica Acta, vol. 300-302, pp. 964-969, 2000.

[153] J.-L. Lan, C.-C. Wan, T.-C. Wei, W.-C. Hsu, and Y.H. Chang, "Durability test of PVP-capped Pt nanoclusters counter electrode for highly efficiency dye-sensitized solar cell," Progress in Photovoltaics: Research and Applications, vol. 20, no. 1, pp. 44-50, 2012.

[154] H. Li, L. Li, and Y. Li, "The electronic structure and geometric structure of nanoclusters as catalytic active sites," Nanotechnology Reviews, vol. 2, no. 5, pp. 515-528, 2013.

[155] T. Imaoka, H. Kitazawa, W. J. Chun, S. Omura, K. Albrecht, and $\mathrm{K}$. Yamamoto, "Magic number $\mathrm{Pt}_{13}$ and misshapen $\mathrm{Pt}_{12}$ clusters: which one is the better catalyst?," Journal of the
American Chemical Society, vol. 135, no. 35, pp. 1308913095, 2013.

[156] V. S. Baidyshev, Y. Y. Gafner, S. L. Gafner, and L. V. Redel, "Thermal stability of Pt nanoclusters interacting to carbon sublattice," Physics of the Solid State, vol. 59, no. 12, pp. 2512-2518, 2017.

[157] S. H. Lee, S. S. Han, J. K. Kang, J. H. Ryu, and H. M. Lee, "Phase stability of Pt nanoclusters and the effect of a (0001) graphite surface through molecular dynamics simulation," Surface Science, vol. 602, no. 7, pp. 1433-1439, 2008.

[158] H. Akbarzadeh and G. A. Parsafar, "A molecular-dynamics study of thermal and physical properties of platinum nanoclusters," Fluid Phase Equilibria, vol. 280, no. 1-2, pp. 16-21, 2009.

[159] M. Farrag, "Preparation, characterization and photocatalytic activity of size selected platinum nanoclusters," Journal of Photochemistry and Photobiology A: Chemistry, vol. 318, pp. 42-50, 2016.

[160] D. Pedone, M. Moglianetti, E. De Luca, G. Bardi, and P. P. Pompa, "Platinum nanoparticles in nanobiomedicine," Chemical Society Reviews, vol. 46, no. 16, pp. 4951-4975, 2017.

[161] J. Niu, X. Wang, J. Lv, Y. Li, and B. Tang, "Luminescent nanoprobes for in-vivo bioimaging," TrAC Trends in Analytical Chemistry, vol. 58, pp. 112-119, 2014.

[162] F. Su, Q. Jia, Z. Li et al., “Aptamer-templated silver nanoclusters embedded in zirconium metal-organic framework for targeted antitumor drug delivery," Microporous and Mesoporous Materials, vol. 275, pp. 152-162, 2019.

[163] S. Jin and K. Ye, "Nanoparticle-mediated drug delivery and gene therapy," Biotechnology Progress, vol. 23, no. 1, pp. 3241, 2007.

[164] A. K. Salem, P. C. Searson, and K. W. Leong, "Multifunctional nanorods for gene delivery," Nature Materials, vol. 2, no. 10, pp. 668-671, 2003.

[165] J. Xu and L. Shang, "Emerging applications of near-infrared fluorescent metal nanoclusters for biological imaging," Chinese Chemical Letters, vol. 29, no. 10, pp. 1436-1444, 2018.

[166] Z. Popović, W. Liu, V. P. Chauhan et al., "A nanoparticle size series for in vivo fluorescence imaging," Angewandte Chemie International Edition, vol. 49, no. 46, pp. 8649-8652, 2010.

[167] V. Parthasarathy, S. Fery-Forgues, E. Campioli, G. Recher, F. Terenziani, and M. Blanchard-Desce, "Dipolar versus octupolar triphenylamine-based fluorescent organic nanoparticles as brilliant one- and two-photon emitters for (bio)imaging," Small, vol. 7, no. 22, pp. 3219-3229, 2011.

[168] A. Shao, X. Wu, and W. Zhu, "Chapter 5. Bioimaging nanomaterials based on near infrared organic dyes," in Near-Infrared Nanomaterials: Preparation, Bioimaging and Therapy Applications, pp. 125-157, Royal Society of Chemistry, 2016.

[169] M. J. Schnermann, "Organic dyes for deep bioimaging," Nature, vol. 551, no. 7679, pp. 176-177, 2017.

[170] M. Bruchez Jr., M. Moronne, P. Gin, S. Weiss, and A. P. Alivisatos, "Semiconductor nanocrystals as fluorescent biological labels," Science, vol. 281, no. 5385, pp. 2013-2016, 1998.

[171] R. Freeman and I. Willner, "Optical molecular sensing with semiconductor quantum dots (QDs)," Chemical Society Reviews, vol. 41, no. 10, pp. 4067-4085, 2012.

[172] X. Shu, A. Royant, M. Z. Lin et al., "Mammalian expression of infrared fluorescent proteins engineered from a bacterial phytochrome," Science, vol. 324, no. 5928, pp. 804-807, 2009. 
[173] F. V. Subach and V. V. Verkhusha, "Chromophore transformations in red fluorescent proteins," Chemical Reviews, vol. 112, no. 7, pp. 4308-4327, 2012.

[174] J.-C. G. Bünzli, "Lanthanide luminescence for biomedical analyses and imaging," Chemical Reviews, vol. 110, no. 5, pp. 2729-2755, 2010.

[175] S. V. Eliseeva and J.-C. G. Bunzli, "Lanthanide luminescence for functional materials and bio-sciences," Chemical Society Reviews, vol. 39, no. 1, pp. 189-227, 2010.

[176] X. Zhang, S. Wang, C. Zhu et al., "Carbon-dots derived from nanodiamond: photoluminescence tunable nanoparticles for cell imaging," Journal of Colloid and Interface Science, vol. 397, pp. 39-44, 2013.

[177] P. Das, M. Bose, S. Ganguly et al., "Green approach to photoluminescent carbon dots for imaging of gram-negative bacteria Escherichia coli," Nanotechnology, vol. 28, no. 19, article $195501,2017$.

[178] U. Resch-Genger, M. Grabolle, S. Cavaliere-Jaricot, R. Nitschke, and T. Nann, "Quantum dots versus organic dyes as fluorescent labels," Nature Methods, vol. 5, no. 9, pp. 763-775, 2008.

[179] W. W. Yu, E. Chang, R. Drezek, and V. L. Colvin, "Water-soluble quantum dots for biomedical applications," Biochemical and Biophysical Research Communications, vol. 348, no. 3, pp. 781-786, 2006.

[180] S. F. Lee and M. A. Osborne, "Brightening, blinking, bluing and bleaching in the life of a quantum dot: friend or foe?," ChemPhysChem, vol. 10, no. 13, pp. 2174-2191, 2009.

[181] M. M. Barroso, "Quantum dots in cell biology," Journal of Histochemistry \& Cytochemistry, vol. 59, no. 3, pp. 237-251, 2011.

[182] X. Le Guével, "Recent advances on the synthesis of metal quantum nanoclusters and their application for bioimaging," IEEE Journal of Selected Topics in Quantum Electronics, vol. 20, no. 3, pp. 45-56, 2014.

[183] L. Ma, V. Andoh, H. Liu, J. Song, G. Wu, and L. Li, "Biological effects of gold nanoclusters are evaluated by using silkworm as a model animal," Journal of Materials Science, vol. 54, no. 6, pp. 4997-5007, 2019.

[184] G. Zuber, E. Weiss, and M. Chiper, "Biocompatible gold nanoclusters: synthetic strategies and biomedical prospects," Nanotechnology, vol. 30, no. 35, article 352001, 2019.

[185] K. Zheng, X. Yuan, N. Goswami, Q. Zhang, and J. Xie, "Recent advances in the synthesis, characterization, and biomedical applications of ultrasmall thiolated silver nanoclusters," RSC Advances, vol. 4, no. 105, pp. 60581-60596, 2014.

[186] X. Chen, J. Zhou, X. Yue et al., "Selective bio-labeling and induced apoptosis of hematopoietic cancer cells using dualfunctional polyethylenimine-caged platinum nanoclusters," Biochemical and Biophysical Research Communications, vol. 503, no. 3, pp. 1465-1470, 2018.

[187] Y. Xin, X. Huang, Z. Li et al., "Versatile Pt NCs-based chemotherapeutic agents significantly induce the apoptosis of cisplatin-resistant non-small cell lung cancer," Biochemical and Biophysical Research Communications, vol. 512, no. 2, pp. 218-223, 2019.

[188] X. Huang, H. Ishitobi, and Y. Inouye, "Formation of fluorescent platinum nanoclusters using hyper-branched polyethylenimine and their conjugation to antibodies for bioimaging," RSC Advances, vol. 6, no. 12, pp. 9709-9716, 2016.
[189] T. Boulikas and M. Vougiouka, "Cisplatin and platinum drugs at the molecular level (review)," Oncology Reports, vol. 10, no. 6, pp. 1663-1682, 2003.

[190] K. Barabas, R. Milner, D. Lurie, and C. Adin, "Cisplatin: a review of toxicities and therapeutic applications," Veterinary and Comparative Oncology, vol. 6, no. 1, pp. 1-18, 2008.

[191] K. N. Sugahara, T. Teesalu, P. P. Karmali et al., "Tissue-penetrating delivery of compounds and nanoparticles into tumors," Cancer Cell, vol. 16, no. 6, pp. 510-520, 2009.

[192] X. Wang, X. Wang, and Z. Guo, "Functionalization of platinum complexes for biomedical applications," Accounts of Chemical Research, vol. 48, no. 9, pp. 2622-2631, 2015.

[193] M. A. Fuertes, C. Alonso, and J. M. Pérez, "Biochemical modulation of cisplatin mechanisms of action: enhancement of antitumor activity and circumvention of drug resistance," Chemical Reviews, vol. 103, no. 3, pp. 645-662, 2003.

[194] N. C. Schmitt and E. W. Rubel, "Osteopontin does not mitigate cisplatin ototoxicity or nephrotoxicity in adult mice," Otolaryngology-Head and Neck Surgery, vol. 149, no. 4, pp. 614-620, 2013.

[195] G. Mandriota, R. Di Corato, M. Benedetti, F. De Castro, F. P. Fanizzi, and R. Rinaldi, "Design and application of cisplatinloaded magnetic nanoparticle clusters for smart chemotherapy," ACS Applied Materials \& Interfaces, vol. 11, no. 2, pp. 1864-1875, 2019.

[196] H. M. Kieler-Ferguson, J. M. J. Fréchet, and F. C. Szoka Jr., "Clinical developments of chemotherapeutic nanomedicines: polymers and liposomes for delivery of camptothecins and platinum(II) drugs," WIREs Nanomedicine and Nanobiotechnology, vol. 5, no. 2, pp. 130-138, 2013.

[197] H. S. Oberoi, N. V. Nukolova, A. V. Kabanov, and T. K. Bronich, "Nanocarriers for delivery of platinum anticancer drugs," Advanced Drug Delivery Reviews, vol. 65, no. 13-14, pp. 1667-1685, 2013.

[198] L. Gatti, G. Cassinelli, N. Zaffaroni, C. Lanzi, and P. Perego, "New mechanisms for old drugs: insights into DNA-unrelated effects of platinum compounds and drug resistance determinants," Drug Resistance Updates, vol. 20, pp. 1-11, 2015.

[199] I. J. Majoros, B. B. Ward, K. H. Lee et al., "Chapter 8 - progress in cancer nanotechnology," in Progress in Molecular Biology and Translational Science, vol. 95, pp. 193-236, Academic Press, 2010.

[200] S. Dilruba and G. V. Kalayda, "Platinum-based drugs: past, present and future," Cancer Chemotherapy and Pharmacology, vol. 77, no. 6, pp. 1103-1124, 2016.

[201] C.-T. Chien, J. Y. Yan, W. C. Chiu, T. H. Wu, C. Y. Liu, and S. Y. Lin, "Caged Pt nanoclusters exhibiting corrodibility to exert tumor-inside activation for anticancer chemotherapeutics," Advanced Materials, vol. 25, no. 36, pp. 5067-5073, 2013.

[202] D. Chen, S. Gao, W. Ge, Q. Li, H. Jiang, and X. Wang, "Onestep rapid synthesis of fluorescent platinum nanoclusters for cellular imaging and photothermal treatment," RSC Advances, vol. 4, no. 76, pp. 40141-40145, 2014.

[203] H. Xia, F. Li, X. Hu et al., "pH-sensitive Pt nanocluster assembly overcomes cisplatin resistance and heterogeneous stemness of hepatocellular carcinoma," ACS Central Science, vol. 2, no. 11, pp. 802-811, 2016.

[204] X. Hu, F. Li, N. Noor, and D. Ling, "Platinum drugs: from $\mathrm{Pt}(\mathrm{II})$ compounds, $\mathrm{Pt}(\mathrm{IV})$ prodrugs, to Pt nanocrystals/nanoclusters," Science Bulletin, vol. 62, no. 8, pp. 589-596, 2017. 
[205] X. Yuan, M. I. Setyawati, D. T. Leong, and J. Xie, "Ultrasmall $\mathrm{Ag}^{+}$-rich nanoclusters as highly efficient nanoreservoirs for bacterial killing," Nano Research, vol. 7, no. 3, pp. 301-307, 2014.

[206] S. B. Subramaniyan, A. Ramani, V. Ganapathy, and V. Anbazhagan, "Preparation of self-assembled platinum nanoclusters to combat Salmonella typhi infection and inhibit biofilm formation," Colloids and Surfaces B: Biointerfaces, vol. 171, pp. 75-84, 2018. 


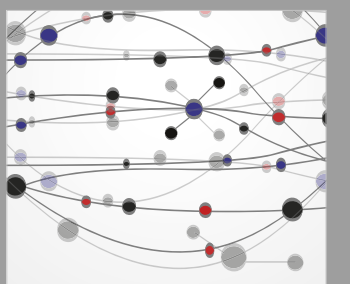

The Scientific World Journal
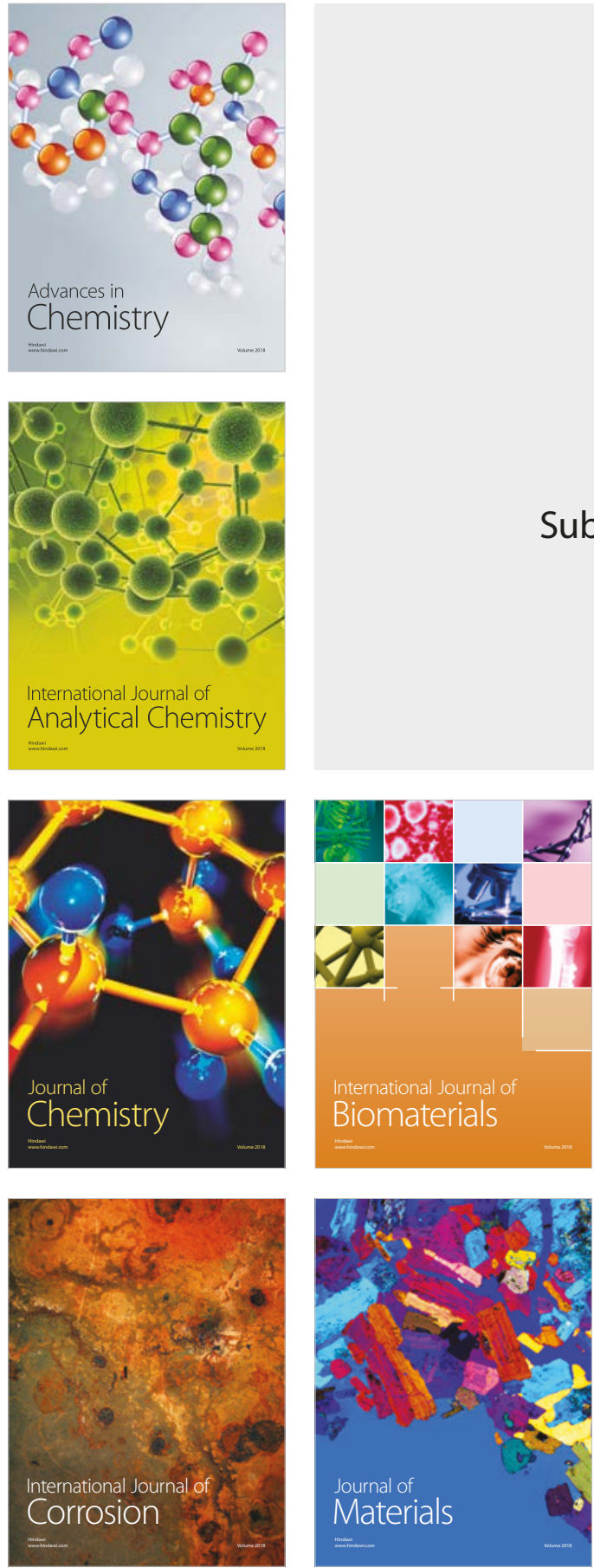

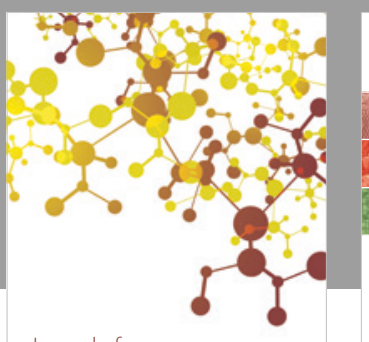

Journal of

Applied Chemistry
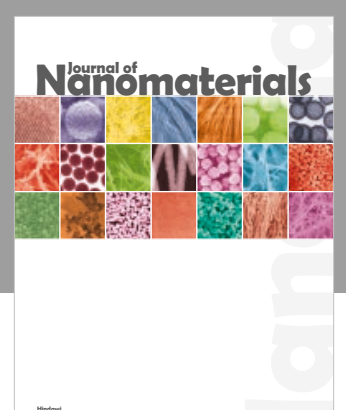

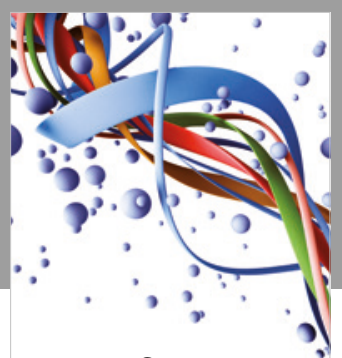

Scientifica

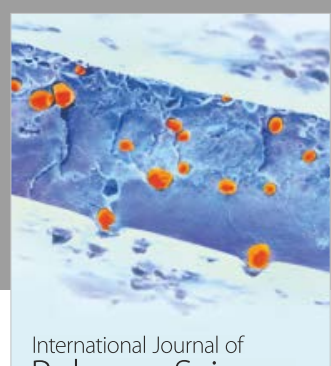

Polymer Science

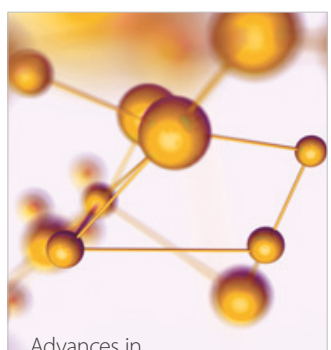

Physical Chemistry
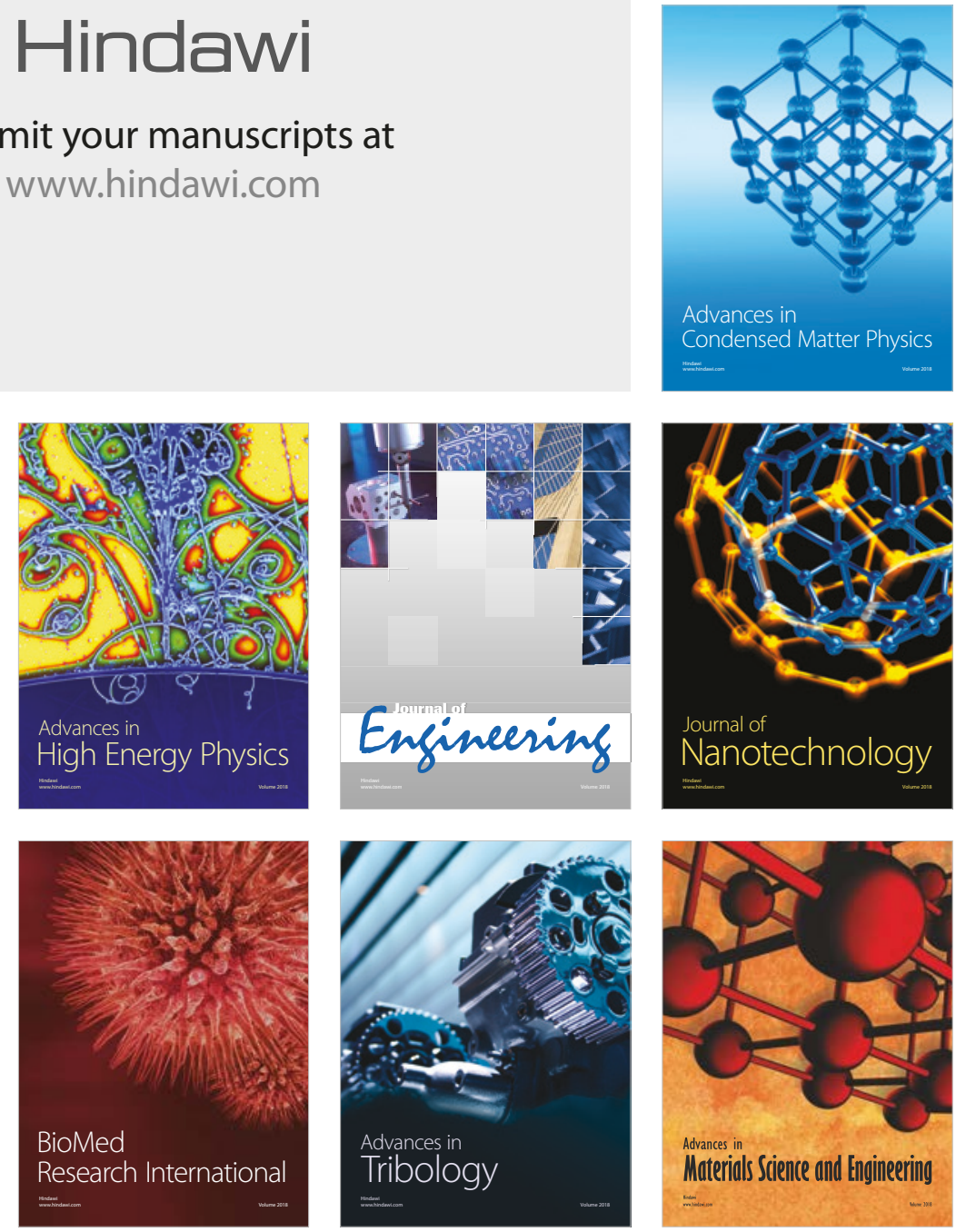